Plane Impact Response of PBX 9501 and Its Components below $2 \mathrm{GPa}$

Jerry J. Dick

A. Richard Martinez

Robert S. Hixson 


\section{DISCLAIMER}

This report was prepared as an account of work sponsored by an agency of the United States Government. Neither the United States Government nor any agency thereof, nor any of their employees, make any warranty, express or implied, or assumes any legal liability or responsibility for the accuracy, completeness, or usefulness of any information, apparatus, product, or process disclosed, or represents that its use would not infringe privately owned rights. Reference herein to any specific commercial product, process, or service by trade name, trademark, manufacturer, or otherwise does not necessarily constitute or imply its endorsement, recommendation, or favoring by the United States Government or any agency thereof. The views and opinions of authors expressed herein do not necessarily state or reflect those of the United States Government or any agency thereof. 


\section{DISCLAIMER}

Portions of this document may be illegible electronic image products. Images are produced from the best available original document. 


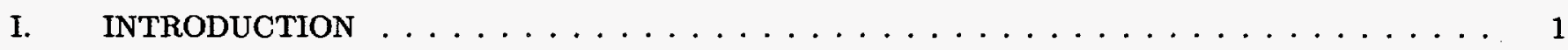

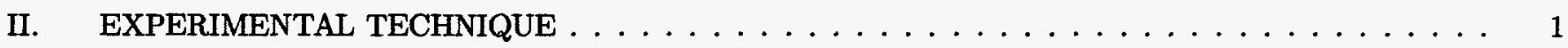

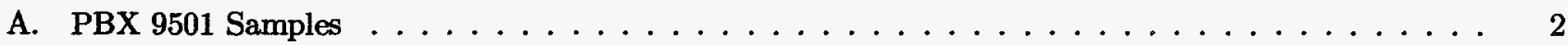

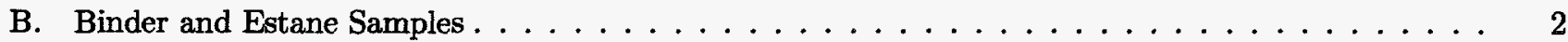

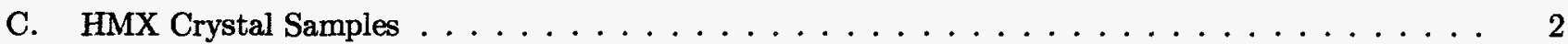

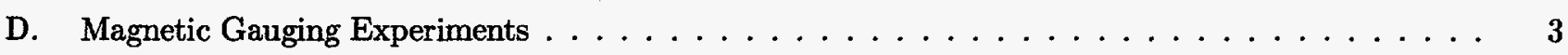

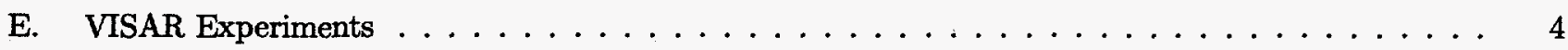

F. Sound Speeds $\ldots \ldots \ldots \ldots \ldots \ldots \ldots \ldots \ldots \ldots \ldots \ldots \ldots \ldots \ldots$

III. SUMMARY OF EXPERIMENTAL RESULTS $\ldots \ldots \ldots \ldots \ldots \ldots \ldots \ldots \ldots \ldots$

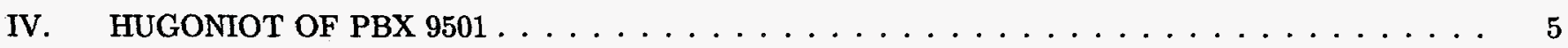

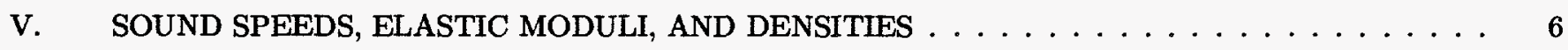

VI. WAVE PROFILE MEASUREMENTS IN PBX $9501 \ldots \ldots \ldots \ldots \ldots \ldots \ldots$

A. Wave Profile Measurements in PBX 9501 near $310 \mathrm{MPa} \ldots \ldots \ldots \ldots$

B. Wave Profile Measurements in PBX 9501 near $580 \mathrm{MPa} \ldots \ldots \ldots \ldots \ldots$

C. Wave Profile Measurements in PBX 9501 at $1.2 \mathrm{GPa} \ldots \ldots \ldots \ldots \ldots$

D. Wave Profile Comparison in PBX 9501 at 0.3 to $1.2 \mathrm{GPa} \ldots \ldots \ldots \ldots \ldots$

E. Elastic Wave Strength in $\operatorname{PBX} 9501 \ldots \ldots \ldots \ldots \ldots \ldots \ldots \ldots \ldots$

F. PBX 9501 Strength vs Strain Rate $\ldots \ldots \ldots \ldots \ldots \ldots \ldots \ldots \ldots \ldots$

G. Wave Profiles in PBX 9501 from 1.6 to $2 \mathrm{GPa} \ldots \ldots \ldots \ldots \ldots \ldots \ldots$

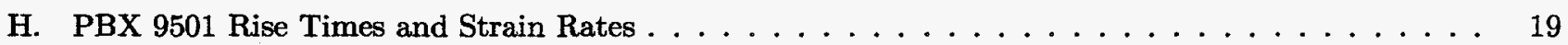

I. Wave Speed as a Function of Particle Speed through the Unsteady Wave . . . . . . . . . . . 19

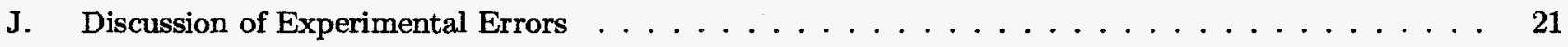

K. Spall Experiments on PBX 9501 at $600 \mathrm{MPa} \ldots \ldots \ldots \ldots \ldots \ldots \ldots \ldots$

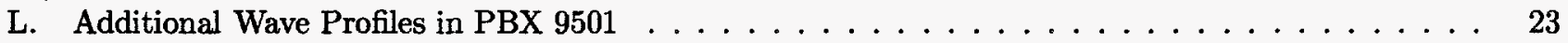

VII. EXPERIMENTS ON THE COMPONENTS OF PBX $9501 \ldots \ldots \ldots \ldots \ldots \ldots$

A. Hugoniot Data and Wave Profiles for PBX 9501 Binder and Estane . . . . . . . . . . . 24

B. Experiments on HMX Single Crystals . . . . . . . . . . . . . . . . 27

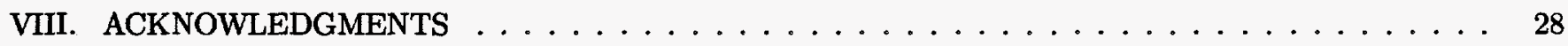

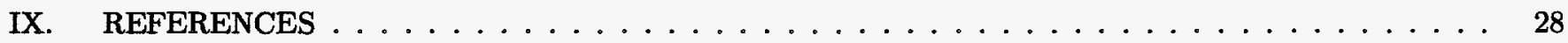




\section{LIST OF FIGURES}

1 Schema of the gun impact experiment with MMV instrumentation. . . . . . . . . . . . . . 3

2 Schema of the gun impact experiment with stirrup gauge instrumentation. . . . . . . . . . . . 3

3 Schema of the gun impact experiment with VISAR instrumentation. . . . . . . . . . . . . 4

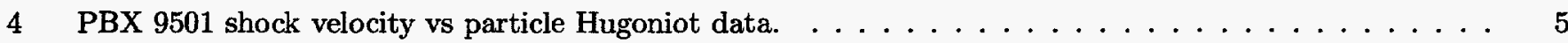

5 Longitudinal stress vs volumetric strain for PBX $9501 \ldots \ldots \ldots \ldots \ldots \ldots \ldots$

6 In-material MMV gauge records in PBX 9501 at $303 \mathrm{MPa}$ in a symmetric impact experiment, 1116. . . 10

7 In-material MMV gauge records in PBX 9501 at $323 \mathrm{MPa}$ in a symmetric impact experiment, 1115. . . 10

8 In-material MIV gauge records in PBX 9501 at $560 \mathrm{MPa}$ in a symmetric impact experiment, 1049. . . 10

9 In-material MIV gauge records in PBX 9501 at $1.18 \mathrm{GPa}$ in a symmetric impact experiment, 1058. . . . 10

10 Comparison of in-material magnetic gauge records in PBX 9501 near $310 \mathrm{MPa}$ at $5.4 \mathrm{~mm}$ depth. . . . 11

11 Summary of experimental wave profiles in PBX 9501 near $310 \mathrm{MPa} \ldots \ldots \ldots \ldots \ldots$

12 Comparison of experimental wave profile records in PBX 9501 at 560 to $580 \mathrm{MPa}$ near $5.4 \mathrm{~mm}$ depth. . 12

13 Summary of experimental wave profiles in PBX 9501 at 560 to $600 \mathrm{MPa} \ldots \ldots \ldots \ldots$

14 Summary of experimental wave profiles in $\mathrm{PBX} 9501$ at $1.2 \mathrm{GPa} \ldots \ldots \ldots \ldots \ldots$

15 Experimental wave profiles in PBX 9501 at $0.30,0.56$, and $1.20 \mathrm{GPa}$ at $5.3 \mathrm{~mm}$ depth. . . . . . . . 13

16 Ultimate compressive strengths and yield stresses vs strain rate for PBX $9501 \ldots \ldots \ldots \ldots$

17 Experimental wave profile records in PBX 9501 at 1.6 to $2 \mathrm{GPa}$ using VISAR instrumentation. . . . . 15

18 Comparison of the wave profile for experiment 1054 in PBX 9501 at $1.2 \mathrm{GPa}$ at the PBX 9501/PMMA interface with a calculation by the MACRAME characteristics code. . . . . . . . . . . . 17

19 Comparison of the experimental wave profile 1053 in PBX 9501 at $1.56 \mathrm{GPa}$ at the PBX 9501/PMMA interface with a calculation by the MACRAME characteristics code. . . . . . . . . . .

20 Comparison of the experimental wave profile 1124 in PBX 9501 at $1.57 \mathrm{GPa}$ at the PBX 9501/PMMA interface with a calculation by the MACRAME characteristics code. . . . . . . . . . . .

21 Comparison of the experimental wave profile 1125 in PBX 9501 at $1.80 \mathrm{GPa}$ at the PBX 9501/PMMA interface with a calculation by the MACRAME characteristics code. . . . . . . . . . . . .

22 Comparison of the experimental wave profile 1136 in Kel-F at $1.66 \mathrm{GPa}$ at the Kel-F/PMMA interface with a calculation by the MACRAME characteristics code. . . . . . . . . . . . . .

23 Comparison of the wave profile for experiment 1081 in PBX 9501 at $1.96 \mathrm{GPa}$ at the PBX 9501/PMMA interface with a calculation by the MACRAME characteristics code. . . . . . . . . . . .

24 Compressive wave rise time vs wave propagation distance for several impact stress levels in PBX 9501. .

25 Comparison of the total strain rates of PBX 9501 for steady waves vs impact stress to the fourth power

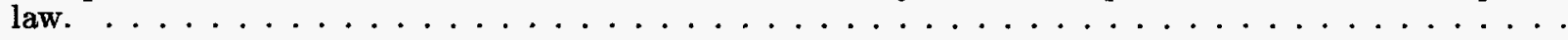

26 Compressive wave phase velocity $C_{u}$ as a function of particle velocity through the unsteady wave for two impact stresses. . . . . . . . . . . . . . . . . . . . .

27 VISAR free-surface record of a spall experiment in PBX 9501 at $0.55 \mathrm{GPa}$, experiment $1084 . \ldots$

28 In-material MMV gauge records in ram-pressed PBX 9501 at $598 \mathrm{MPa}$ in a symmetric impact experiment,

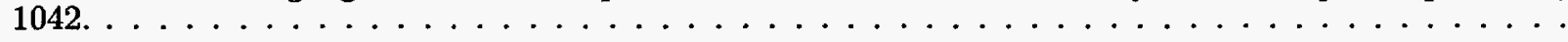

29 Distorted in-material MMV gauge records in PBX 9501 at about $300 \mathrm{MPa}$ in a symmetric impact exper-

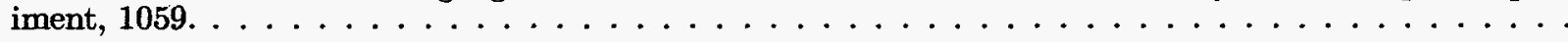

30 Shock velocity vs particle velocity Hugoniot data for estane and PBX 9501 binder. . . . . . . . .

31 Pressure-volume Hugoniot for estane. The new data are the blue points. . . . . . . . . . . . . .

32 VISAR interface records for PBX 9501 binder at the interface with PMMA at 198, 420, and $1040 \mathrm{MPa}$ impact stresses. . . . . . . . . . . . . . . . . . . . .

33 Particle velocity profiles for estane at the interface with PMMA. Impact stresses are 190, 340, and

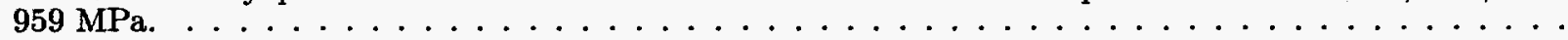

34 Particle velocity profiles of elastic-plastic waves in HMX single crystals for crystals with 110 and 011 faces. 28 


\section{LIST OF TABLES}

1 Results of Impact Experiments on PBX $9501 \ldots \ldots \ldots \ldots \ldots \ldots \ldots \ldots \ldots$

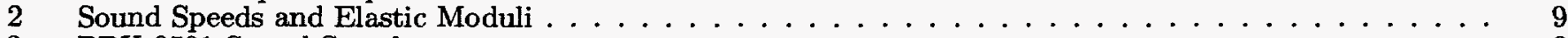

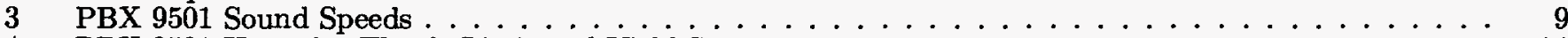

$4 \quad$ PBX 9501 Hugoniot Elastic Limit and Yield Stress . . . . . . . . . . . . . . . . . . . . . . 14

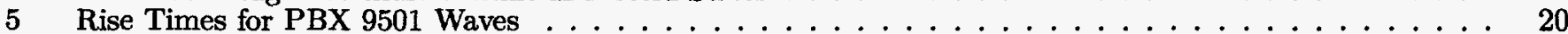

6 Results of VISAR Experiments on PBX 9501 Binder and Estane . . . . . . . . . . . . . . . 25 


\title{
Plane Impact Response of PBX 9501 and Its Components below 2 GPa
}

\author{
by
}

\author{
Jerry J. Dick, *A. Richard Martinez, and Robert S. Hixson
}

\begin{abstract}
The Hugoniot equation of state was measured for PBX 9501, the binder, and estane below $2 \mathrm{GPa}$ using a light-gas gun facility. Time-resolved wave profiles were also obtained for these materials as well as for HMX single crystals in a state of uniaxial strain. The dynamic strength of PBX 9501 was measured at high strain rates in both compression and tension. In addition, elastic moduli were obtained from measurements of longitudinal and shear sound speeds.
\end{abstract}

\section{INTRODUCTION}

The problem of accidental detonation of explosive due to a mechanical insult is of continuing concern. The insult may not begin as a shock, but data from plane impact experiments provide equation of state data and the mechanical response at high strain rates in a well-defined state of uniaxial strain. In these experiments we have measured impact response from $200 \mathrm{MPa}$ to $2 \mathrm{GPa}$ and impact velocities down to $120 \mathrm{~m} / \mathrm{s}$. There was essentially no existing data in this region for PBX 9501 or its components. The low end overlaps the range of stresses found in the spigot test, Steven test ${ }^{1}$, and other multidimensional tests. ${ }^{2}$ The results should enhance understanding of impact tests on PBX's and serve as a basis for testing models used in computation of hazards problems. The experimental results are presented in considerable detail, so that workers in these areas will have a complete description of the experiments.

Studying the components is of interest since there are models for computing the response of the composite material from the constitutive properties of the components. The binder is $5 \%$ of the PBX by weight and $7.2 \%$ by volume. By weight the binder is half estane and half nitroplasticizers. Actually, $0.1 \mathrm{wt} \%$ of an antioxidant is added

\footnotetext{
*Electronic mail:jjd@lanl.gov
}

as well. The response of estane itself is of interest to see if a good description can be obtained for it as an elastomer. There is interest in changes in molecular weight of estane over time. Migration of the nitroplasticizer is also of interest.

\section{EXPERIMENTAL TECHNIQUE}

Plane impact experiments were performed on PBX 9501 and its components with shock strengths from $200 \mathrm{MPa}$ to $2 \mathrm{GPa}(0.1 \mathrm{GPa}=1 \mathrm{kbar}=100 \mathrm{MPa}=14.50 \mathrm{ksi})$ obtained using a light-gas gun facility. Argon was used for the propellant below about $400 \mathrm{~m} / \mathrm{s}$ and helium above that. Time-resolved wave profiles of particle velocity were measured using magnetic gauges in one of two configurations or using VISAR ${ }^{\dagger}$ laser interferometry. The experimental arrangements are depicted in Figs. 1 to 3 . In the case of magnetic gauges, in-material wave profiles were measured; in the case of VISAR experiments the profiles were measured at the interface between the material and a PMMA (polymethylmethacrylate)f window or vacuum. The laser beam is reflected from the mirror at the interface with spot size of about $0.5 \mathrm{~mm}$ at the center of the sample. The average target chamber temperature was $20.7 \pm 2.3^{\circ} \mathrm{C}$. Den-

†VISAR stands for velocity interferometer system for any reflector. 
sities were measured by water immersion.

For low velocities the projectile body was made of brass with a Lexan polycarbonate nose and had a mass of about $4.8 \mathrm{~kg}$. For high velocities the projectile body was either Lexan or 2024 aluminum. The impactors for symmetric impact experiments with PBX 9501 were $50.8 \mathrm{~mm}$ in diameter. Three VISAR experiments 1053, 1054, and 1062 had impactors $50.8 \mathrm{~mm}$ in diameter flush-mounted in an aluminum projectile, but backed by PMMA $8 \mathrm{~mm}$ thick. The remaining experiments had impactors $57.2 \mathrm{~mm}$ in diameter and were backed by a microballoon foam or polyurethane foam with a density of about $0.48 \mathrm{~g} / \mathrm{cm}^{3}$.

The samples of PBX 9501 were $50.8 \mathrm{~mm}$ in diameter and the samples of estane and binder were $38 \mathrm{~mm}$ in diameter. The samples were bonded to the aluminum target plate with epoxy, Sylgard 184 elastomer, or Aralhex polyurethane glue. For VISAR experiments the samples were placed in a $51 \mathrm{~mm}$ dia hole in the aluminum target plate $6 \mathrm{~mm}$ thick. The impact face of the sample was nearly flush with the front face of the plate; the impact face typically was 50 to $75 \mu \mathrm{m}$ above the aluminum plate. For magnetic experiments the samples were mounted on the front of the plate so that the gauges were about 15 to $25 \mathrm{~mm}$ above the plate. In this way the dynamic measurements were made before the shock wave reached the metal plate and disturbed the magnetic field.

\section{A. PBX 9501 Samples}

With one exception, all PBX 9501 samples were from $13.5 \times 13.5 \times 3.5$-inch blocks hydrostatically pressed at $\mathrm{S}$ Site from Holston lot 89C730-010 under the supervision of Manny Chavez. The drawback of this lot is that it was not possible to achieve densities within the desired range of 1.828 to $1.838 \mathrm{~g} / \mathrm{cm}^{3}$ by hydrostatic pressing. The average density of the samples was $1.827 \pm 0.001 \mathrm{~g} / \mathrm{cm}^{3}$. However, there was no immediate alternative available for hydrostatically pressed material. It was believed that for mechanical response this should not cause a significant difference. Four possible variations are lot, pressing type, density, and age. The specification density could be achieved by ramdie pressing. But ram-die pressing is believed to cause variation in density and particle size with radius and distance from the ram. Furthermore, it is not the pressing technique of interest.

\section{B. Binder and Estane Samples}

The binder samples were fabricated at Building 360 at SSite by Robert Montoya with supervision by John Kramer. A thin layer was poured onto a cookie sheet or into a muffin tin. Solvent was allowed to evaporate, and then another layer was poured. In this way samples up to $6 \mathrm{~mm}$ thick were made. The material is red, soft, and rubbery. Samples $38 \mathrm{~mm}$ in diameter were cut out with a cork borer. The surfaces were finished by a surface grinder at room temperature. The samples were thickest in the center with about a $50 \mu \mathrm{m}$ variation in thickness. Samples were bonded to a flat PMMA window and then placed on a flat surface. Then they were cast in epoxy so that a flat impact face was achieved. The average and peak molecular weights of the estane in the binder were measured as $1.5 \times 10^{5}$ and $1.2 \times 10^{5} \mathrm{~g} / \mathrm{mol}$ by Wayne King.

The estane samples were hot-pressed under vacuum to $15 \mathrm{ksi}$ at S-Site from lot 6812100SK13, DA95171-01 flakes under the supervision of Cindy Sandoval. The flakes are coated with talc to prevent sticking during storage. The pressing was $15 \mathrm{~cm}$ in diameter and $3.5 \mathrm{~cm}$ thick. Samples $38 \mathrm{~mm}$ in diameter and up to $10 \mathrm{~mm}$ thick were machined at Hand Precision Machining by blowing liquid nitrogen over the surface to freeze it without freezing the main mass. Thickness varied by up to $110 \mu \mathrm{m}$ on samples used in experiments. The estane sample disks are thickest in the center. Both average and peak molecular weights were .73 $\times 10^{5} \mathrm{~g} / \mathrm{mol}$ in this form.

For both binder and estane the PMMA window was bonded to the sample and the sample cast into a $51-\mathrm{mm}$ dia hole in the target plate with epoxy.

\section{HMX Crystal Samples}

The HMX (cyclotetramethylene-tetranitramine) crystal slabs about $10 \mathrm{~mm}$ in lateral dimension were mounted on 


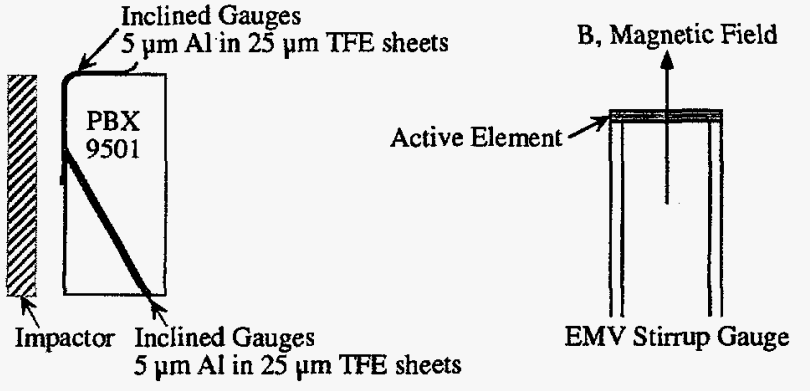

Figure 1: Schema of the gun impact experiment with MMV instrumentation. Gauge positions are marked in red. The gauge leads and insulation are marked in blue.

aluminum-coated, Kel- $\mathrm{F}^{*}$ impact discs with a silicone elastomer. It was deemed important to not impact the crystals directly in order to avoid spurious effects at the impact face. The crystal and PMMA window were bonded together with a silicone elastomer and surrounded with a casting of epoxy loaded with 40 vol \% fused silica in order to reduce edge effects. The epoxy loaded with silica is a good impedance match for explosives.

The HMX crystal slabs were cut from larger crystals using a low-speed, diamond saw. The crystals were polished using a series of polishing sheets consisting of alumina embedded in plastic. Soap and water were used as the carrier. The crystals were water-clear and inspected with a binocular microscope at magnifications up to $50 \mathrm{x}$ to make sure that the interiors were free of inclusions and other visible defects larger than about $2 \mu \mathrm{m}$. Crystals were grown by Howard Cady a number of years ago.

\section{Magnetic Gauging Experiments}

Magnetic gauges operate according to Maxwell's third relation. The shock-induced motion of the gauge active element is perpendicular to the magnetic field. Therefore, the induced voltage is $\epsilon=B u l$, where $B$ is the magnetic field of about $0.750 \mathrm{kgauss}, u$ is the particle velocity induced by the shock in $\mathrm{mm} / \mu \mathrm{s}$, and $l$ is the length of the gauge active element in $\mathrm{cm}$. The length is 0.6 to $1.0 \mathrm{~cm}$.

Two types of magnetic gauging experiments were per-

${ }^{*} \mathrm{Kel}-\mathrm{F}$ is polytrifluorochloroethylene manufactured by the $3 \mathrm{M}$ Company.

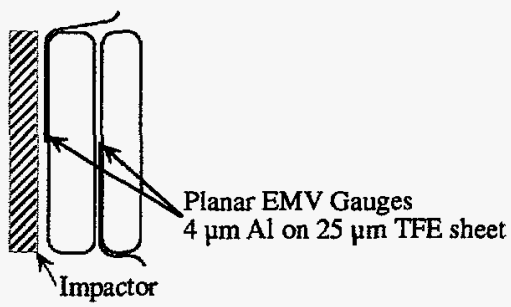

Figure 2: Schema of the gun impact experiment with stirrup gauge instrumentation. Gauge positions are marked in red. The gauge leads and insulation are marked in blue.

formed on PBX 9501. Magnetic impulse and particle velocity (MIV) gauge packages consisting of 5 nested gauges of each type are placed side by side sandwiched between sheets of Teflon $25 \mu \mathrm{m}$ thick (See Fig. 1.). The nested particle velocity gauges are 6 to $10 \mathrm{~mm}$ wide. The active elements were made of aluminum $5 \mu \mathrm{m}$ thick. The gauge active elements are spaced $2 \mathrm{~mm}$ apart in the sandwich so that when placed in the sample at an angle of $30^{\circ}$ the gauges are successively $1 \mathrm{~mm}$ deeper into the explosive sample. Some experiments were performed with two sets of nested particle velocity (MMV, multiple magnetic velocity) gauges.

Many of the earlier experiments had a nested set of triangular gauges designed to measure impulse in addition to the rectangular particle velocity gauges, MIV gauges (magnetic impulse and velocity gauges). The intent was to use the two types of gauges in concert in order to perform Lagrangian analysis on the data. ${ }^{3}$ In this way stress-strain curves could be obtained for loading and unloading at several depths in the sample. However, it has become clear that a robust, straightforward, Lagrangian analysis of that type requires a fitting form for the data surfaces other than polynomials such as are used currently.

The second type consists of two particle velocity gauges (EMV, electromagnetic velocity, stirrup) with 10-mm-wide active elements. These gauges are emplaced parallel to the shock impact face as in Fig. 2. One is placed on the impact face, and one is placed between two pieces of explosive of varying thicknesses. The gauge package consists of the aluminum gauge on one sheet of Teflon. 


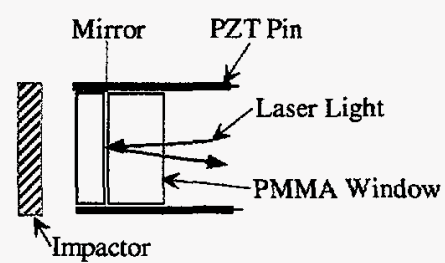

Figure 3: Schema of the gun impact experiment with VISAR instrumentation.

The samples of PBX 9501 were $50.8 \mathrm{~mm}$ in diameter. For magnetic experiments the samples were bonded to the face of the target plate and had free lateral surfaces. For stirrup gauge shots the PBX 9501 disks were bonded to a 9 to $12 \mathrm{~mm}$ thick plastic disk in order to offset the gauges from the aluminum target plate and avoid eddy currents in it due to shock-induced motion during the gauge recording time.

\section{E. VISAR Experiments}

For VISAR studies, PMMA (Mil. Spec. P-5425D, preshrunk) windows were used, Fig. 3. The mirrors were either vapor-plated aluminum or $13-\mu \mathrm{m}$-thick aluminum foil.

The surface of the PMMA adjacent to the crystal was coated with a diffuse aluminum mirror for VISAR particle velocity measurements. Roughening the PMMA surface with $9-\mu \mathrm{m} \mathrm{Al}_{2} \mathrm{O}_{3}$ embedded in a plastic film gave a satisfactory roughness for a diffuse reflector. Some repolishing can be done to get more light back into the receiving lens of the fiber optic probe. In some cases a $13 \mu \mathrm{m}$ thick aluminum foil was used for the mirror instead of a vapor plated mirror.

The samples of PBX 9501 were $50.8 \mathrm{~mm}$ in diameter and the samples of estane and binder were $38 \mathrm{~mm}$ in diameter. For VISAR experiments the samples were bonded to the PMMA window or aluminum foil mirror and glued in a $50 \mathrm{~mm}$ dia hole in the aluminum target plate. Two piezoelectric pins were emplaced on the impact face of the sample on opposite sides of a diameter. The time difference between shock arrival at these pins and the shock arrival signal recorded by the VISAR allowed measurement of transit time through the crystal and from that the wave velocities. It is important to account for the difference in signal travel times to the digitizing oscilloscopes for the two types of signals.

The measurement system used was a push-pull, VISAR system. ${ }^{4}$ Some experiments were performed with two VISARs and some with one VISAR. Using two VISARs with different fringe constants removes ambiguity in determining the particle-velocity jump at the shock when extra fringes must be added. This is important when initiation of the explosive sample occurs. The light was transported from the argon-ion laser to the target and thence to the interferometer table with fiber optics. The fiber optic probe on the target was obtained from Valyn International. It has a focal spot size of $0.6 \mathrm{~mm}$. The light interference signals were converted to voltage using photomultiplier tubes with rise and fall times of about $1 \mathrm{~ns}$. The signals were recorded on digitizers at 1 or 2 ns sampling rates. Judging by the Lissajous figures generated by combining the signals that are $90^{\circ}$ out of phase, the overall response time of the system is about $3 \mathrm{~ns}$ at the shock-wave arrival time.

\section{F. Sound Speeds}

Sound wave velocities were measured with a pulse-echo apparatus, the same apparatus used by Stan Marsh and Bart Olinger at Ancho Canyon for many years. A burst of acoustic energy is emitted from a $5 \mathrm{MHz}$ transducer. Round trip echo times are measured with a receiving transducer. The moduli computed from the acoustic signals correspond to the limit of infinitesimal strain and high strain rate. Materials measured were PBX 9501, PBX 9501 binder, estane, HMX crystals, and Kel-F. Most of the materials studied were very dispersive. Therefore, signal averaging was used to measure signals from weak echoes. Sample thickness for sound speed measurement was typically 1 to $1.5 \mathrm{~mm}$ for these materials. 


\section{SUMMARY OF EXPERIMENTAL RESULTS}

Wave profiles of particle velocity vs time were obtained for PBX 9501 at about $0.3,0.6,1.2,1.6$, and 2.0 GPa. For PBX 9501 there were no reliable Hugoniot data below 2 GPa. Hugoniot equation of state data were obtained on PBX 9501, binder, estane, and HMX single crystals. For estane there were no data below $1 \mathrm{GPa}$. Furthermore, the intercept of the existing shock velocity vs particle velocity Hugoniot at zero particle velocity was not in agreement with the bulk sound velocity. No Hugoniot data existed for the binder, or for HMX single crystals below $35 \mathrm{GPa}$.

In PBX 9501 multiple embedded magnetic gauge records were obtained at $0.3,0.6$ and $1.2 \mathrm{GPa}$ with 5 particle velocity histories at 1.4 to $5.4 \mathrm{~mm}$. These were symmetric impact experiments with PBX 9501 impactors. In this way the final particle velocity is required to be half the accurately measured projectile velocity. This is a check on the accuracy of the MIV gauges. At $0.3 \mathrm{GPa} 2$ experiments with stirrup gauges at $5.4 \mathrm{~mm}$ depth were performed in order to check repeatability and agreement with the multiple embedded gauges that are in the sample on a plane slanted $30^{\circ}$ with respect to the shock plane. Similarly, one stirrup gauge experiment was performed at $0.6 \mathrm{GPa}$. At 0.3 and $0.6 \mathrm{GPa}$ stirrup gauge experiments were performed with 8-mm thick PBX 9501 samples and VISAR experiments with $10 \mathrm{~mm}$ thick samples. In addition, wave profiles were obtained with VISAR instrumentation on samples $5 \mathrm{~mm}$ thick at 1.2, 1.6, 1.8 and 2.0 GPa. There was evidence of initiation at 1.6 to $2.0 \mathrm{GPa}$.

For the binder and estane VISAR experiments were performed at about 200,400 , and $1000 \mathrm{MPa}$. From the experimental results Hugoniot points and particle velocity histories were obtained.

For HMX single crystals two VISAR experiments were performed to measure the strength of the elastic precursor in two crystal orientations. The two orientations were 110 and 011 in the space group $P 21 / n$; the impact plane was parallel to those planes. Impact stress was about 1.4 GPa.

Discussion of the several kinds of results on the different materials follows.

\section{HUGONIOT OF PBX 9501}

Hugoniot data for PBX 9501 are displayed in Fig. 4. A fit to the Hugoniot data given in Table 1 and the data in Ref. 5 for densities 1.832 to $1.844 \mathrm{~g} / \mathrm{cm}^{3}$ is

$$
U_{S}=2.40+2.39 u_{p}, \quad 0<u<0.9 \mathrm{~mm} / \mu \mathrm{s},
$$

where $U_{S}$ is shock velocity or wave velocity at half the maximum particle velocity, and $u_{p}$ is final particle velocity. The standard errors of the fit parameters are 0.03 , and 0.07 , respectively. The root mean squared (RMS) error of the shock velocity is $0.09 \mathrm{~mm} / \mu \mathrm{s}$.

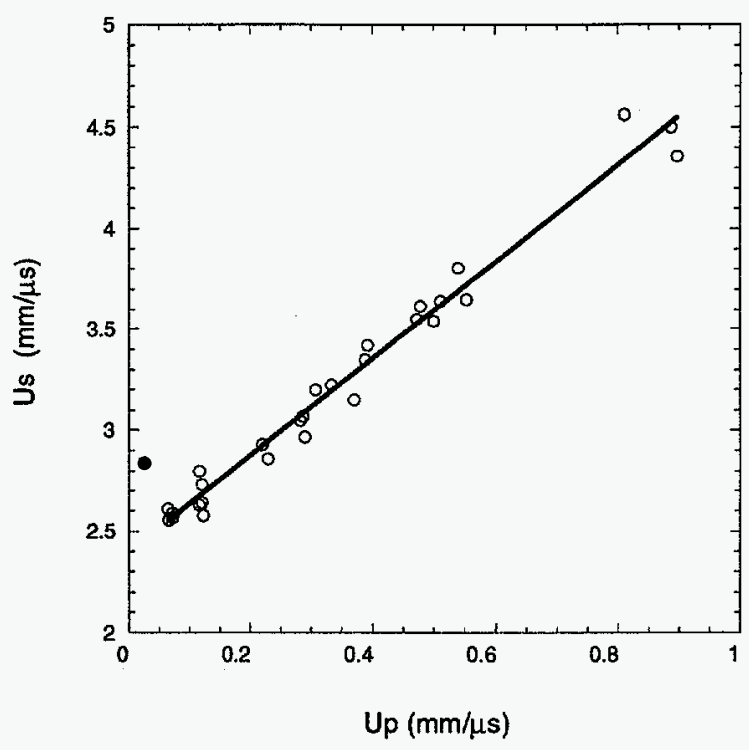

Figure 4: PBX 9501 shock velocity vs particle Hugoniot data. The solid blue circle is the average Hugoniot elastic limit point.

The two data points below $600 \mathrm{MPa}$ in Ref. 5 were not used as their validity is questionable. Those points were obtained using a streak camera and assumed a sharp shock. Our new wave profile measurements show that this is not the case at such low longitudinal stresses. Rise times are on the order of a microsecond after several millimeters of wave propagation.

The two spall experiments, 1082 and 1084 , at $550 \mathrm{MPa}$ were not used as the samples were only $3 \mathrm{~mm}$ thick. This 
increases the uncertainty in wave velocity due to errors in measuring the transit time. Also, the wave is very unsteady in this region. The measured, apparent, wave speeds are low compared to other measurements at this stress level. If they are included the fit is

$$
U_{S}=2.37+2.44 u_{p}, \quad 0<u<0.9 \mathrm{~mm} / \mu \mathrm{s}
$$

The standard errors of the fit parameters are 0.03 , and 0.08 , respectively. The RMS error of the shock velocity is $0.10 \mathrm{~mm} / \mu \mathrm{s}$.

The wave profiles are unsteady up to $600 \mathrm{MPa}$ for propagation distances up to about $8 \mathrm{~mm}$. The Hugoniot jump conditions for conservation of mass and momentum apply only to discontinuities or steady waves. The Hugoniot curve is the locus of end states on the thermodynamic equilibrium surface for the material for shocks taking the material from the initial state to the final state. Approximate Hugoniot states were obtained by taking the transit time for the particle velocity on the wave front equal to half the final particle velocity for the entire wave. It must be kept in mind that some of the Hugoniot data at or below $600 \mathrm{MPa}$ are approximate because of the unsteadiness of the wave for the first $8 \mathrm{~mm}$ of propagation distance; the wave profile and rise time changes as it propagates in that distance. Using the particle velocity for the entire wave may systematically make the wave velocities near $0.3 \mathrm{GPa}$ a bit high relative to the others. But it was decided to not overanalyze the data by trying to treat the unsteady, dispersive, wave front as two waves for Hugoniot points.

The data are displayed as stress vs strain in Fig. 5 . Volumetric strain is $-\left(V-V_{0}\right) / V_{0}=1-V / V_{0}$, where $V_{0}$ is the specific volume in the initial state. The Hugoniot data represent the locus of end states for the compressive waves. The locus describes a curve on the thermodynamic surface of the material. Ten percent uniaxial strain is reached at about $1.8 \mathrm{GPa}$ and $20 \%$ at about $7 \mathrm{GPa}$.

Table 1 lists the measured Hugoniot data for PBX 9501. The measured shock velocity, $U_{S}$, is given in column seven. The Hugoniot state in PBX 9501 for the leading shock is computed using impedance matching techniques. For symmetric impact experiments the particle velocity is half the

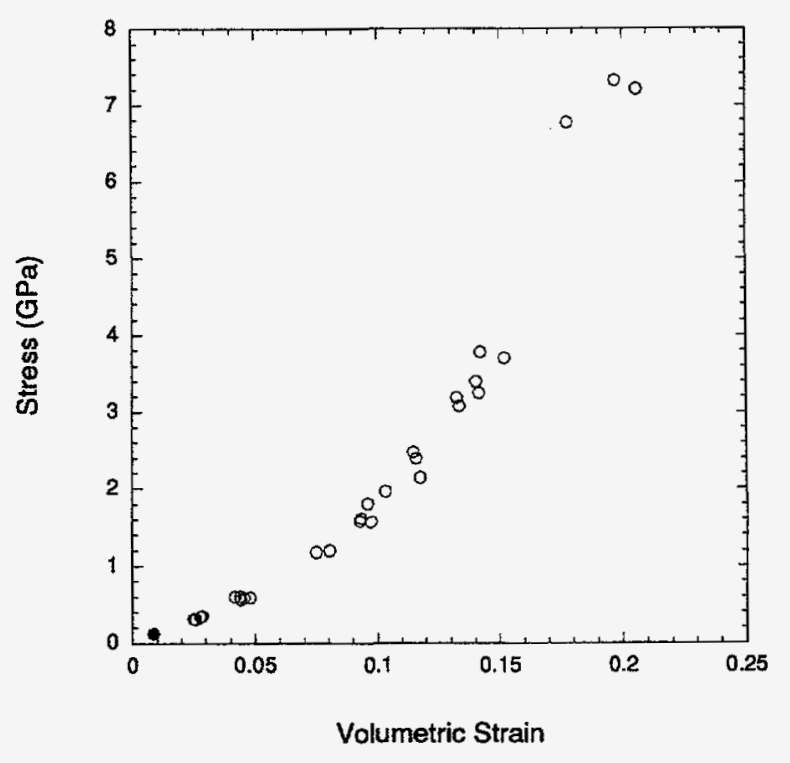

Figure 5: Longitudinal stress vs volumetric strain for PBX 9501. The volumetric strain is $1-V / V_{0}$.

impactor velocity. In other cases the particle velocity is computed from the intersection of the Rayleigh line for the sample and the reflected Hugoniot of the impactor originating at the impactor velocity in the stress vs particle velocity plane.

A $30^{\circ}$ MMV experiment, 1075, by Rick Gustavsen on PBX 9501 with a density of $1.826 \mathrm{~g} / \mathrm{cm}^{3}$ gave a particle velocity of 0.510 and a shock velocity of 3.64 for an impact stress of 3.39. This point agrees well with the existing wedge Hugoniot points in that region with higher PBX 9501 densities.

\section{SOUND SPEEDS, ELASTIC MODULI, AND DENSITIES}

An isotropic material has just two independent elastic constants. Therefore, all elastic moduli can be calculated from two independent sound speeds, e.g., longitudinal $C_{L}$ and shear $C_{S}$. The shear modulus $G$ is $\rho_{0} C_{S}^{2}$. The bulk modulus is

$$
K=\rho_{0} C_{0}^{2}=\rho_{0}\left[C_{L}^{2}-\frac{4}{3} C_{S}^{2}\right]
$$


Table 1: Results of Impact Experiments on PBX 9501

\begin{tabular}{|c|c|c|c|c|c|c|c|c|c|}
\hline $\begin{array}{l}\text { Shot } \\
\text { num. }\end{array}$ & $\begin{array}{c}\text { Experiment } \\
\text { type }\end{array}$ & $\begin{array}{c}\text { Impactor, } \\
\mathrm{d} \\
(\mathrm{mm})\end{array}$ & $\begin{array}{c}\text { Sample }^{a} \\
\rho_{0} \\
\left(\mathrm{~g} / \mathrm{cm}^{3}\right)\end{array}$ & $\begin{array}{l}\text { Thick- } \\
\text { ness } \\
(\mathrm{mm})\end{array}$ & $\begin{array}{c}u_{I} \\
(\mathrm{~mm} / \mu \mathrm{s})\end{array}$ & $\begin{array}{c}\mathrm{U}_{S} \\
(\mathrm{~mm} / \mu \mathrm{s})\end{array}$ & $\begin{array}{c}\mathrm{u}_{\mathrm{p}}^{b} \\
(\mathrm{~mm} / \mu \mathrm{s})\end{array}$ & $\begin{array}{c}P_{x}^{b} \\
(\mathrm{GPa})\end{array}$ & $\epsilon_{x}^{b}$ \\
\hline 1115 & MMV & $9501,3.02$ & 1.826 & $1.33-5.27$ & 0.1325 & 2.67 & 0.0662 & 0.323 & 0.025 \\
\hline 1116 & MMV & $9501,2.80$ & 1.825 & $1.32-5.27$ & 0.1322 & 2.51 & 0.0661 & 0.303 & 0.026 \\
\hline 1071 & Stirrup & Kel-F, 4.19 & 1.827 & 5.405 & 0.133 & 2.56 & 0.066 & 0.307 & 0.026 \\
\hline 1072 & Stirrup & Kel-F, 4.19 & 1.828 & 7.993 & 0.134 & 2.61 & 0.065 & 0.310 & 0.025 \\
\hline 1061 & VISAR & Kel-F, 5.89 & 1.827 & 10.018 & 0.148 & 2.59 & 0.072 & 0.341 & 0.028 \\
\hline 1070 & Stirrup & Kel-F, 4.19 & 1.827 & 5.415 & 0.149 & 2.57 & 0.074 & 0.345 & 0.029 \\
\hline 1049 & MIV & $9501,3.01$ & 1.827 & $1.42-5.4$ & 0.233 & 2.63 & 0.116 & 0.560 & 0.044 \\
\hline 1117 & Stirrup & $\mathrm{z}-\mathrm{qtz}, 6.36$ & 1.826 & 5.39 & 0.1585 & 2.58 & 0.1236 & 0.582 & 0.048 \\
\hline 1073 & Stirrup & Kel-F, 4.83 & 1.827 & 7.976 & 0.248 & 2.64 & 0.120 & 0.579 & 0.045 \\
\hline 1060 & VISAR & Kel-F, 5.89 & 1.828 & 10.018 & 0.247 & 2.73 & 0.120 & 0.599 & 0.044 \\
\hline 1042 & MIV & $9501,3.23$ & 1.835 & $1.38-5.32$ & 0.233 & 2.80 & 0.116 & 0.598 & 0.042 \\
\hline $1082^{c}$ & VISAR & $\mathrm{z}-\mathrm{qtz}, 3.02$ & 1.827 & 3.028 & 0.1576 & 2.44 & 0.125 & 0.556 & 0.051 \\
\hline $1084^{c}$ & VISAR & $\mathrm{z-qtz}, 3.03$ & 1.827 & 3.01 & 0.1530 & 2.47 & 0.121 & 0.546 & 0.049 \\
\hline 1058 & MIV & $9501,2.99$ & 1.828 & $1.37-5.33$ & 0.441 & 2.93 & 0.220 & 1.18 & 0.075 \\
\hline 1054 & VISAR & z-qtz, 2.55 & 1.826 & 5.04 & 0.300 & 2.86 & 0.230 & 1.20 & 0.080 \\
\hline 1053 & VISAR & $\mathrm{z-qtz}, 2.57$ & 1.825 & 5.016 & 0.380 & 2.97 & 0.289 & 1.56 & 0.097 \\
\hline 1062 & VISAR & z-qtz, 2.56 & 1.828 & 4.982 & 0.381 & 3.07 & 0.287 & 1.61 & 0.094 \\
\hline 1124 & VISAR & z-qtz, 3.010 & 1.826 & 10.015 & 0.3754 & 3.05 & 0.2825 & 1.57 & 0.093 \\
\hline 1125 & VISAR & z-qtz, 3.007 & 1.828 & 4.956 & 0.4140 & 3.20 & 0.3080 & 1.80 & 0.096 \\
\hline 1081 & VISAR & z-qtz, 6.37 & 1.823 & 4.538 & 0.446 & 3.22 & 0.333 & 1.96 & 0.103 \\
\hline $1075^{d}$ & MMV & - & 1.826 & - & - & 3.64 & 0.510 & 3.39 & 0.140 \\
\hline
\end{tabular}

${ }^{a}$ The PBX 9501 samples were all hydrostatically pressed from Holston lot 89C730-010 except for the one used in shot 1042. It was ram-pressed from another lot.

${ }^{b}$ Values were calculated from the intersection of the Rayleigh line and the appropriate reflected impactor Hugoniot using the wave velocity at half maximum particle velocity, the measured impactor velocity and the known impactor Hugoniot. In cases of symmetric impact the particle velocity was taken as half the impactor velocity. In stirrup gauge shots the particle velocity was taken as that measured by the gauge on the impact face, and the wave velocity was taken from the transit time between gauges. For VISAR shots the state was computed from the measured wave velocity and finding the intersection of the Rayleigh line and the reflected impactor Hugoniot.

${ }^{c}$ The primary purpose of these shots was measurement of spall strength. The pulse from the impactor was $1 \mu \mathrm{s}$ in duration, and the spall pullback occurred at the rear surface before the final amplitude of the transmitted pulse was recorded at the rear free surface. Consequently, these factors along with the thin sample thickness and small transit time apparently reduce the accuracy of a Hugoniot point computed from this experiment. They appear to be outliers, and were not used in the Hugoniot fit.

${ }^{d}$ These data were acquired by Rick Gustavsen using $30^{\circ} \mathrm{MMV}$ gauges. 
Poisson's ratio is

$$
\nu=0.5\left[1-\frac{1}{\left(\frac{C_{L}}{C_{S}}\right)^{2}-1}\right]
$$

Young's modulus is expressed as

$$
E=\frac{\rho_{0}\left(3 C_{L}^{2}-4 C_{S}^{2}\right)}{\left(\frac{C_{L}}{C_{S}}\right)^{2}-1}
$$

Longitudinal and shear wave velocities were measured for PBX 9501 binder, estane, HMX crystals and Kel-F. The results along with moduli are given in Table 2. Values for a type of copper are given for comparison.

The moduli of polymers and PBX 9501 are rate dependent. From sound speeds the Young's modulus for PBX 9501 is $9.56 \mathrm{GPa}$. In contrast, a value of $0.77 \mathrm{GPa}$ was measured in Instron tests. ${ }^{6}$ The ratio of high to low strain rate Young's modulus is 12.4. The Young's modulus for estane from Instron tensile data is about $7.6 \mathrm{MPa}^{7}$ In comparison the high strain rate value from sound speeds is $340 \mathrm{MPa}, 45$ times greater. Noteworthy among the moduli are the low shear moduli and corresponding Poisson's ratios near 0.5 for the binder and estane. These values are typical of rubber and elastomers.

The longitudinal modulus, $\rho_{0} C_{L}^{2}$, of PBX 9501 is 16.8 GPa. For the two HMX crystal orientations the average value is $26.6 \pm 0.3 \mathrm{GPa}$. In comparison, the $c_{11}$ elastic constant of $\mathrm{HMX}$ is $20 \mathrm{GPa}$ and the $\mathrm{c}_{33}$ is $21 \mathrm{GPa} .8$

The sound speed values for PBX 9501 are the ones measured by Bart Olinger some 20 years ago. ${ }^{9}$ His explosive was ram/die pressed. We tried to measure the longitudinal sound speed on some current material. PBX 9501 was very dispersive. A single echo was obtained with a sample $1 \mathrm{~mm}$ thick. The shift in time of that echo was measured by adding another piece $1.5 \mathrm{~mm}$ thick. Three different lots of PBX 9501 were tested in this manner. Dises $25 \mathrm{~mm}$ of the two thicknesses in diameter were machined from larger discs, typically $50 \mathrm{~mm}$ in diameter and 3 to $5 \mathrm{~mm}$ thick. Densities were measured on the larger discs at S-Site and on the small discs at TA-9. The results are shown in Ta- ble 3. The longitudinal sound speeds measured currently are all lower than Olinger's. For comparison, the velocity of the leading foot of the elastic shock for $600 \mathrm{MPa}$ impact stresses was about 2.92 for hydropressed Holston lot 89C730-010. For one experiment from Holston lot 85G730007 , ram-pressed material with a density of $1.835 \mathrm{~g} / \mathrm{cm}^{3}$ the leading foot of the wave had a velocity of $3.00 \mathrm{~mm} / \mu \mathrm{s}$.

The variation in the density measured at two different times and places on the parent piece and on parts machined from it is larger than expected. Two $25 \mathrm{~mm}$ dia dises were machined from each of the three parent pieces. The variation in density of the pairs of $25 \mathrm{~mm}$ dia pieces measured at TA-9 were $0.001,0.004$, and $0.003 \mathrm{~g} / \mathrm{cm}^{3}$, respectively.

\section{WAVE PROFILE MEASUREMENTS IN PBX 9501}

Wave profiles were measured in PBX 9501 at about 0.3, 0.6, 1.2, 1.6, 1.8, and $2 \mathrm{GPa}$. Embedded, $30^{\circ}$, nested magnetic experiments were performed at $0.3,0.6$, and $1.2 \mathrm{GPa}$. The experiments at $0.3 \mathrm{GPa}$ had a stirrup gauge emplaced on the center of the impact face. The measured profiles for the Holston lot 89C730-010 are shown in Figs. 6 to 9 .

At $0.31 \mathrm{GPa}$ we see long rise times that evolve with propagation distance and a subtle two-wave structure developing at the last two gauges (Figs. 6 and 7). There is a change in slope just below $30 \mathrm{~m} / \mathrm{s}$. The first wave is the elastic wave, and the change in slope defines the elastic limit. The inelastic wave is dispersive and unsteady. The unloading wave is recorded as well. The same behavior is noted at $0.6 \mathrm{GPa}$ (Fig. 8). At 1.2 GPa the wave has sharpened up considerably, but there is an apparent shoulder at the end of the sharp rise (Fig. 9). At late times the agreement with half the projectile velocity is quite good at 1.2 $\mathrm{GPa}$, within $1 \%$ for the last 4 gauges. At $0.6 \mathrm{GPa}$ the particle velocity at late times is 0.4 to $3.0 \%$ high. At 0.3 GPa the final state on the first embedded gauge is $0.6 \%$ low in experiment 1116 and $4.7 \%$ low in experiment 1115 . At subsequent gauges the final state is not reached before the rarefaction arrives. 
Table 2: Sound Speeds and Elastic Moduli

\begin{tabular}{ccccccccc}
\hline Material & $\begin{array}{c}\text { Density } \\
\left(\mathrm{g} / \mathrm{cm}^{3}\right)\end{array}$ & $\begin{array}{c}\mathrm{C}_{L} \\
(\mathrm{~mm} / \mu \mathrm{s})\end{array}$ & $\begin{array}{c}\mathrm{C}_{S} \\
(\mathrm{~mm} / \mu \mathrm{s})\end{array}$ & $\begin{array}{c}\mathrm{C}_{0} \\
(\mathrm{~mm} / \mu \mathrm{s})\end{array}$ & $\nu$ & $\begin{array}{c}\mathrm{K} \\
(\mathrm{GPa})\end{array}$ & $\begin{array}{c}G \\
(\mathrm{GPa})\end{array}$ & $\begin{array}{c}\mathrm{E} \\
(\mathrm{GPa})\end{array}$ \\
\hline PBX 9501 & 1.82 & 2.97 & 1.39 & 2.50 & 0.36 & 11.4 & 3.52 & 9.56 \\
binder & 1.27 & 1.72 & 0.28 & 1.69 & 0.49 & 3.65 & 0.100 & 0.30 \\
estane & 1.19 & 1.79 & 0.31 & 1.75 & 0.48 & 3.69 & 0.115 & 0.34 \\
HMX SX $\{110\}_{n}$ & 1.90 & 3.76 & & & & & & \\
HMX SX \{011 $\}_{n}$ & 1.90 & 3.72 & & & & & & \\
Kel-F & 2.14 & 1.89 & 0.75 & 1.68 & 0.41 & 6.04 & 1.20 & 3.39 \\
copper & 8.94 & 4.75 & 2.30 & 3.94 & 0.35 & 138. & 47.3 & 127. \\
\hline
\end{tabular}

Table 3: PBX 9501 Sound Speeds

\begin{tabular}{ccccc}
\hline $\begin{array}{c}\text { PBX 9501 } \\
\text { type }\end{array}$ & $\begin{array}{c}\text { pressing } \\
\text { type }\end{array}$ & $\begin{array}{c}\mathrm{S}^{\text {S-Site }} \\
\text { density } \\
\left(\mathrm{g} / \mathrm{cm}^{3}\right)\end{array}$ & $\begin{array}{c}\mathrm{TA}^{3} 9^{a} \\
\text { density } \\
\left(\mathrm{g} / \mathrm{cm}^{3}\right)\end{array}$ & $\begin{array}{c}\mathrm{C}_{L} \\
(\mathrm{~mm} / \mu \mathrm{s})\end{array}$ \\
\hline $89 \mathrm{C730-010}$ & hydro & 1.827 & 1.821 & 2.87 \\
unknown & hydro & 1.834 & 1.830 & 2.86 \\
Blend 622-7 & ram & - & 1.826 & 2.78 \\
Olinger's & ram & - & 1.82 & 2.97
\end{tabular}

${ }^{a}$ The S-Site densities are those of the parent pieces about $50 \mathrm{~mm}$ in diameter and about $5 \mathrm{~mm}$ thick, whereas the TA-9 densities are of the $25 \mathrm{~mm}$ diameter by $1.5 \mathrm{~mm}$ thick pieces used in the sound speed measurements that were machined from the parent pieces. 


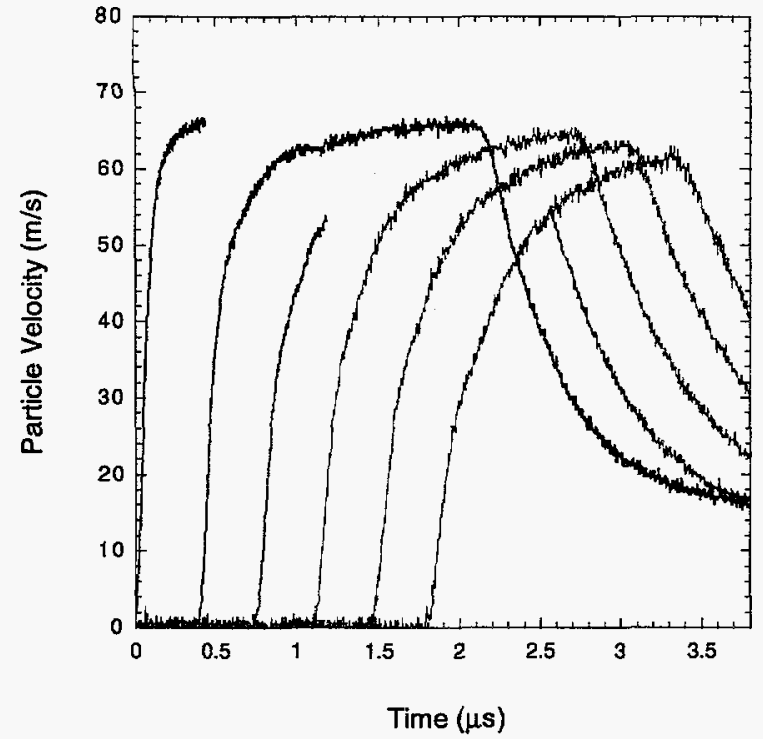

Figure 6: In-material MMV gauge records in PBX 9501 at $303 \mathrm{MPa}$ in a symmetric impact experiment, 1116. Gauge positions are 1.32 to $5.27 \mathrm{~mm}$ in from impact face. Half the impact velocity is $66.2 \mathrm{~m} / \mathrm{s}$. The middle part of the second record at $2.32 \mathrm{~mm}$ was lost. The impact-face gauge leads were potted in epoxy flush with the impact face. The hydrodynamic flow near the lateral edge apparently caused gauge-lead spreading and anomalous increases in voltage level. Therefore, only the first part of the impact face record is displayed.

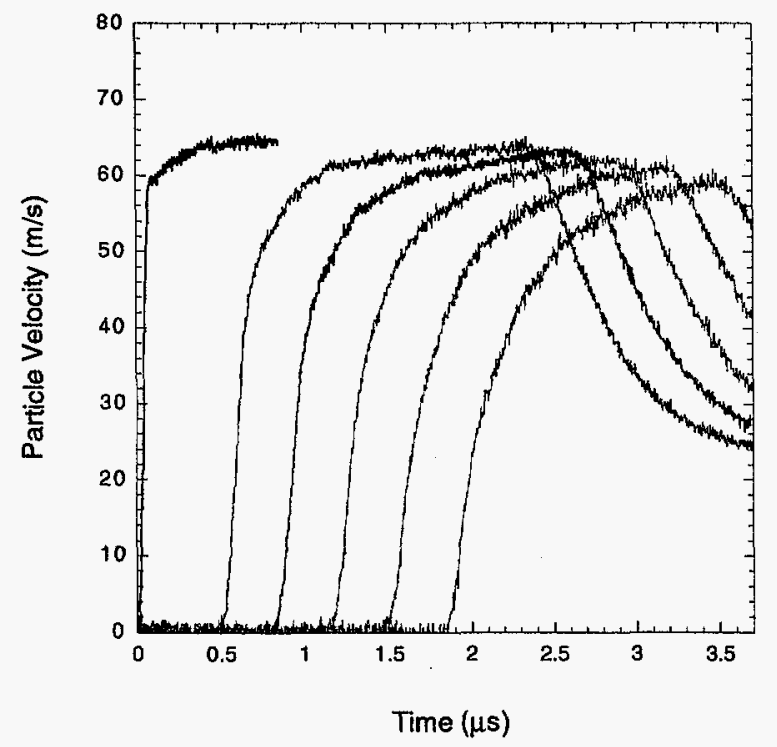

Figure 7: In-material MMV gauge records in PBX 9501 at $323 \mathrm{MPa}$ in a symmetric impact experiment, 1115. Gauge positions are 1.33 to $5.27 \mathrm{~mm}$ in from impact face. Half the impact velocity is $66.1 \mathrm{~m} / \mathrm{s}$.

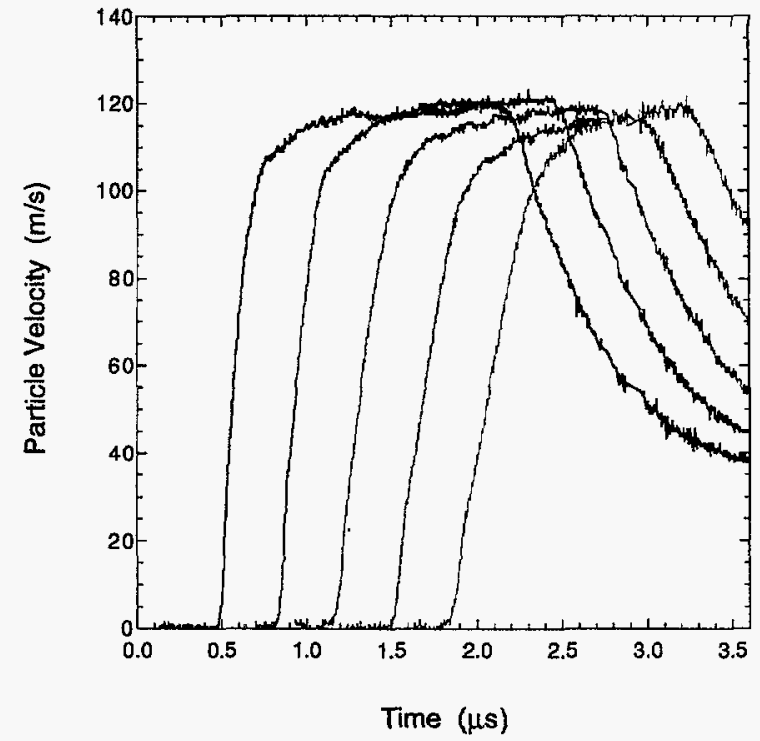

Figure 8: In-material MIV gauge records in PBX 9501 at $560 \mathrm{MPa}$ in a symmetric impact experiment, 1049. Gauge positions are 1.38 to $5.32 \mathrm{~mm}$ in from impact face. Half the impact velocity is $116 \mathrm{~m} / \mathrm{s}$.

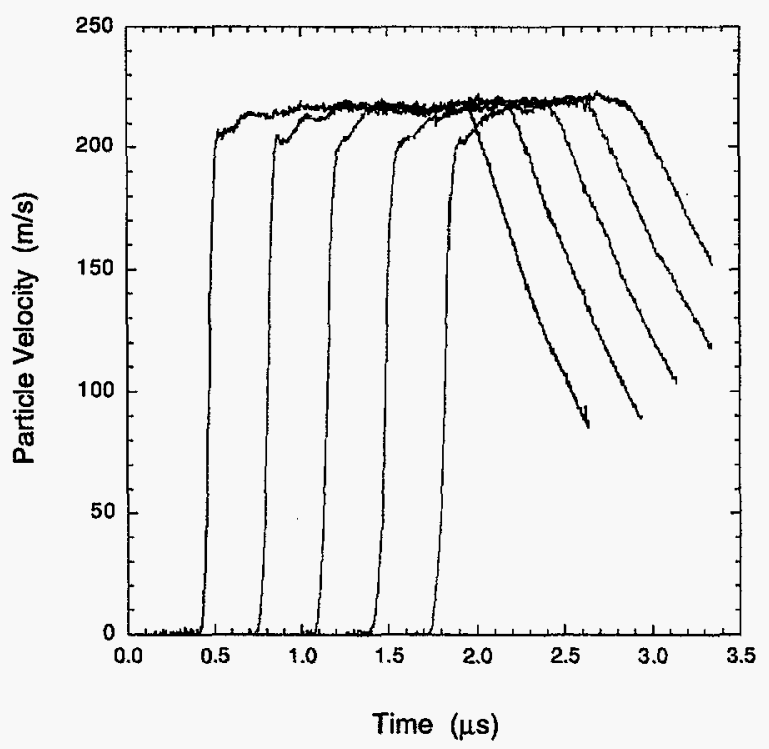

Figure 9: In-material MIV gauge records in PBX 9501 at $1.18 \mathrm{GPa}$ in a symmetric impact experiment, 1058. Gauge positions are 1.37 to $5.33 \mathrm{~mm}$ in from impact face. Half the impact velocity is $220 \mathrm{~m} / \mathrm{s}$. The origin of time is calculated as the distance to the first gauge divided by the longitudinal sound speed. 


\section{A. Wave Profile Measurements in PBX 9501 near $310 \mathrm{MPa}$}

In addition to the MMV gauging measurements, three stirrup gauge measurements were made (two at $5.4 \mathrm{~mm}$ and one at $8 \mathrm{~mm}$ ) as well as a VISAR measurement with a $10 \mathrm{~mm}$ thick sample. The two stirrup gauges at 5.4 $\mathrm{mm}$ and at 307 and $345 \mathrm{MPa}$ agree very well with the MMV record at $5.27 \mathrm{~mm}$ from experiment 1116 at 303 MPa (Fig. 10). This shows that the profile measurements are repeatable on PBX 9501 at the same density, from the same lot, and pressed in the same way. This also demonstrates that gauges emplaced at $30^{\circ}$ to the impact plane agree well with gauges emplaced parallel to the impact plane and the wave front.

The VISAR experiment measures the particle velocity history at the interface between the explosive and the PMMA mirror. In addition, the experiments did not have exactly the same impact stress. In order to display all profiles on the same plot, it was decided to normalize the measured particle velocities by the expected final particle velocities. For symmetric impact the final particle velocity is half the projectile velocity; for VISAR and experiments with two stirrup gauges it was the value calculated from the known Hugoniots including the Hugoniot of PBX 9501 using Joe Fritz's MACRAME characteristics code.

A summary of experiments near $310 \mathrm{MPa}$ for the same lot of PBX 9501 is displayed in Fig. 11. A front-surface impact record is shown from experiment 1072. The interferometric record for the VISAR experiment at $10 \mathrm{~mm}$ was only half a fringe for the fringe constant used. This short of a record resulted in poor accuracy for the particle velocity profile obtained. The final level was about $10 \%$ low. Therefore the record was scaled by 1.10 in order to bring it in line with the other records and the final particle velocity calculated by MACRAME.

\section{B. Wave Profile Measurements in PBX 9501 near $580 \mathrm{MPa}$}

The results of experiment 1049 at $560 \mathrm{MPa}$ are displayed in Fig. 8. The rise times are sharper than at $310 \mathrm{MPa}$ but

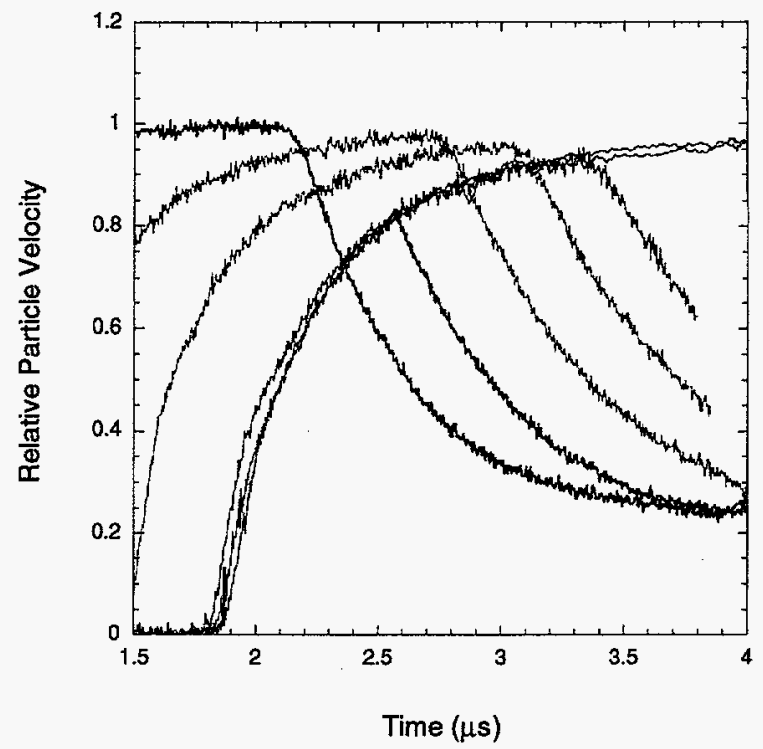

Figure 10: In-material magnetic gauge records in PBX 9501 near $310 \mathrm{MPa}$. It shows the relative particle velocity profiles for two stirrup gauge experiments, 1070 and 1071, at $5.4 \mathrm{~mm}$ depth compared to the MMV gauge profile at $5.27 \mathrm{~mm}$ from experiment 1116 (magenta).

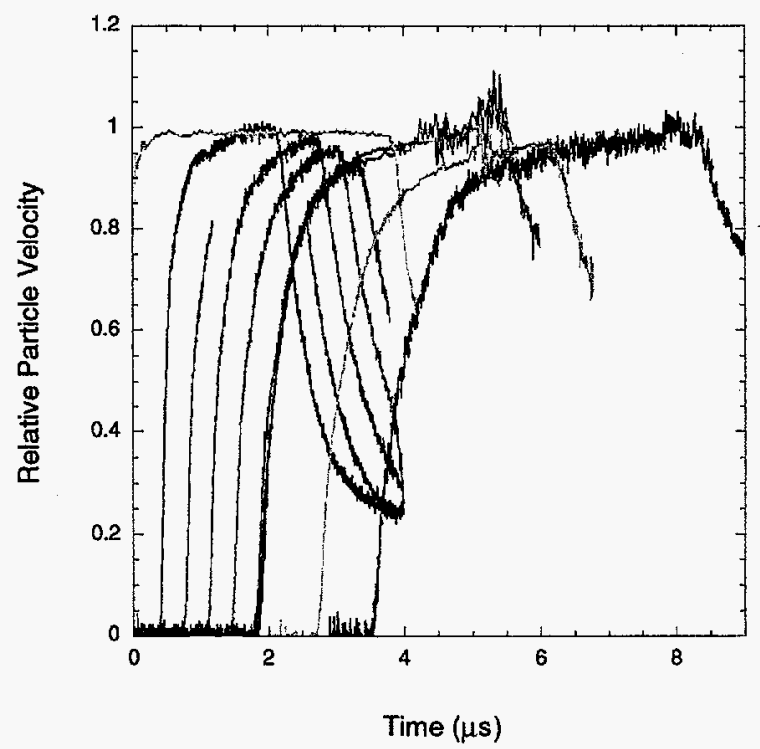

Figure 11: Experimental wave profiles in $\mathrm{PBX}$ 9501 near $310 \mathrm{MPa}$ for lot 89C730-010 hydrostatically pressed to a density of $1.827 \pm 0.001 \mathrm{~g} / \mathrm{cm}^{3}$. The two orange profiles are from stirrup gauges for experiment 1072. The last record is from a VISAR experiment 1061. 
the wave is still unsteady, the profile changing as it propagates. A stirrup gauge experiment 1117 was performed at about $5.37 \mathrm{~mm}$ for comparison with the last gauge in experiment 1049 that had the gauges emplaced at $30^{\circ}$ to the impact plane at $5.39 \mathrm{~mm}$. The comparison is shown in Fig. 12. The agreement in wave front profiles is good, similar to the results at $310 \mathrm{MPa}$. Both types of gauge emplacements perform well. The slanted gauges appear to show a sharper change in slope between the elastic and inelastic waves at a relative particle velocity of about 0.25 . A summary of all records near $580 \mathrm{MPa}$ plotted as relative particle velocity is shown in Fig. 13.

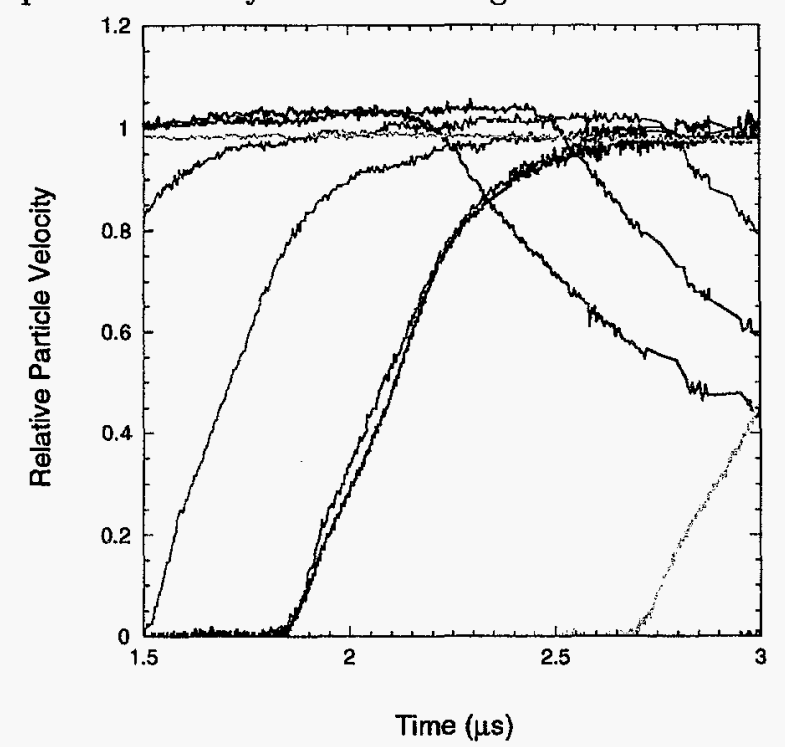

Figure 12: Experimental wave profile records in PBX 9501 at 560 to $580 \mathrm{MPa}$. Comparison of wave profiles at $5.4 \mathrm{~mm}$ depth from a magnetic gauge embedded at $30^{\circ}$ to the impact face (magenta curve) and one embedded parallel to the impact face (black curve).

\section{Wave Profile Measurements in PBX 9501 at $1.2 \mathrm{GPa}$}

The comparison of the nested, embedded, magnetic gauge records from experiment 1058 at depths from 1.37 to $5.33 \mathrm{~mm}$ are compared to the VISAR record for experiment 1054 at $1.20 \mathrm{GPa}$ with a sample $5.04 \mathrm{~mm}$ thick in Fig. 14. The rise times agree quite well, and the VISAR record confirms the hesitation in the wave front rise at 92 to $95 \%$ of the final state.

The z-cut quartz impactor in the VISAR experiment was

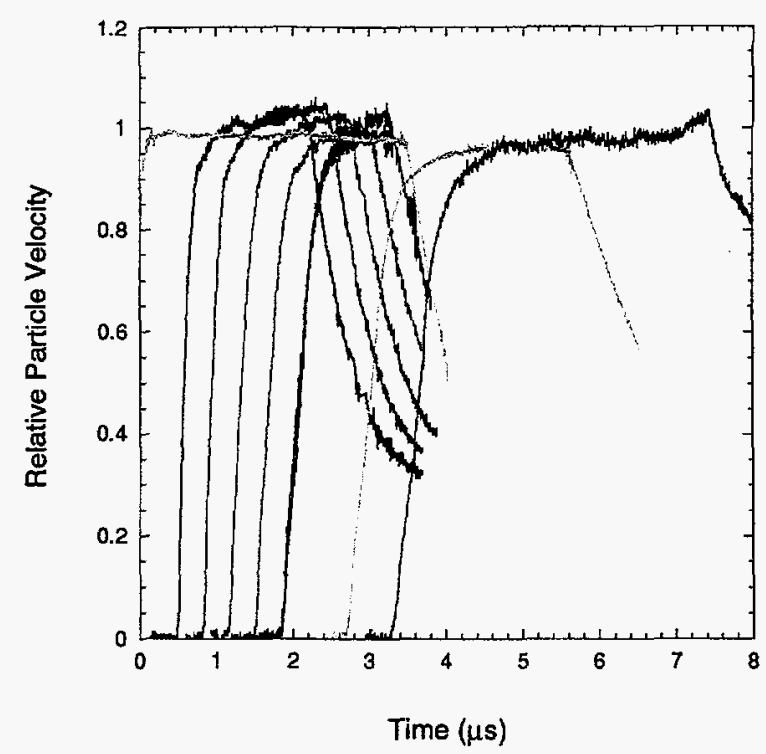

Figure 13: Experimental wave profiles in PBX 9501 at 560 to $600 \mathrm{MPa}$. The two orange profiles are for experiment 1073. The last record is from a VISAR experiment 1060 .

only $2.55 \mathrm{~mm}$ thick. The shock velocity in the impactor was $6.46 \mathrm{~mm} / \mu \mathrm{s}$; therefore the rarefaction overtook the wave front before the final state was reached after $5 \mathrm{~mm}$ of wave propagation in PBX 9501.

The question arises whether the elastic wave is overdriven by $1.2 \mathrm{GPa}$. The velocity measured for the beginning of the wave rise is $2.94 \mathrm{~mm} / \mu \mathrm{s}$ in experiment 1054 and $2.99 \mathrm{~mm} / \mu \mathrm{s}$ in experiment 1058 . Thus the longitudinal elastic wave is on the verge of being overdriven at 1.2 GPa. Results of experiments by Bob Graham and G. T. Holman at Sandia using polyvinylidene fluoride (PVDF) gauges show evidence of a two-wave structure in the derivative of the particle velocity at 1.2 GPa in PBX 9501. For comparison, the measured speed of the leading disturbance is $3.09 \pm 0.06 \mathrm{~mm} / \mu \mathrm{s}$ at $1.58 \mathrm{GPa}, 3.29 \mathrm{~mm} / \mu \mathrm{s}$ at 1.80 $\mathrm{GPa}$, and $3.27 \mathrm{~mm} / \mu$ s at $1.96 \mathrm{GPa}$.

\section{Wave Profile Comparison in PBX 9501 at 0.3 to $1.2 \mathrm{GPa}$}

A comparison of the wave front rise times and profiles from 0.3 to $1.2 \mathrm{GPa}$ after about $5.3 \mathrm{~mm}$ of wave propagation is displayed in Fig. 15. These are records from the multiple nested magnetic gauge experiments 1116, 1049 , and 1054. It shows the dramatic sharpening of the wave 


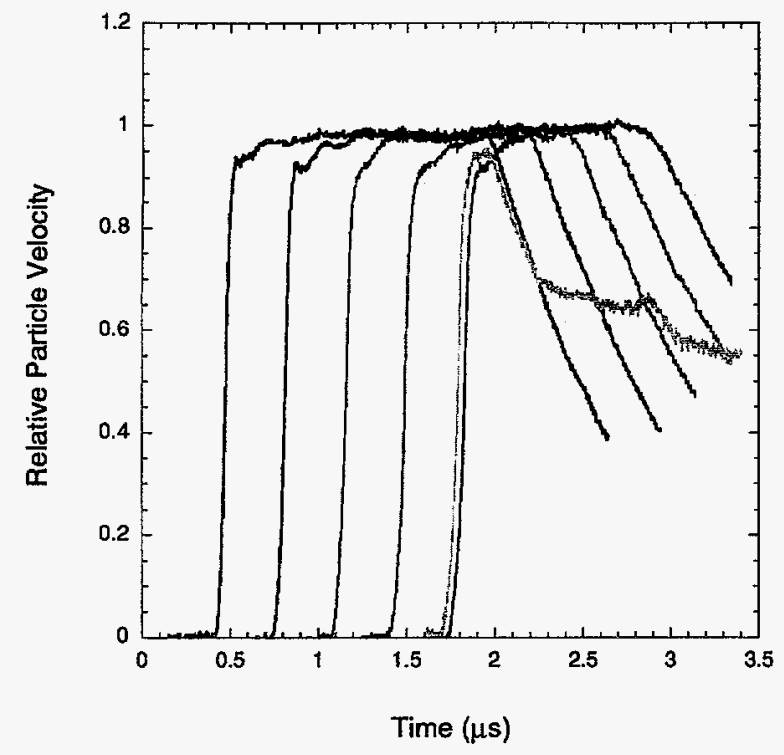

Figure 14: Experimental wave profiles in PBX 9501 at $1.2 \mathrm{GPa}$. The nested magnetic gauges are at 1.37 to $5.33 \mathrm{~mm}$ depth. The VISAR record is at $5.04 \mathrm{~mm}$.

front as the impact stress increases. It is typical of many materials that the rise time decreases and the strain rate increases as the impact stress increases.

It should be mentioned that the time of impact (time zero) was measured with a stirrup gauge at $0.3 \mathrm{GPa}$. For the other two experiments it was computed from the position of the first gauge divided by the appropriate longitudinal sound speed for defining the time of first motion at the first gauge.

\section{E. Elastic Wave Strength in PBX 9501}

The elastic wave is discernible in experiments near 300 and $600 \mathrm{MPa}$. In some measurements the end of the elastic wave is delineated by a subtle two-wave structure, in others by a change in slope of the wave profile. The measured Hugoniot elastic limits (yield point in uniaxial compressive strain at high strain rates) are listed in Table 4. Corresponding yield stresses in uniaxial stress $\mathrm{Y}$ are calculated from $^{10}$

$$
Y=\left[\frac{1-2 \nu}{1-\nu}\right] \sigma_{x}^{H E L} .
$$

For samples from lot $89 \mathrm{C} 730-010$ the average Hugoniot elastic limit is $123 \pm 8 \mathrm{MPa}$ for impact stresses of about $310 \mathrm{MPa}$ and $150 \pm 15 \mathrm{MPa}$ for impact stresses of about

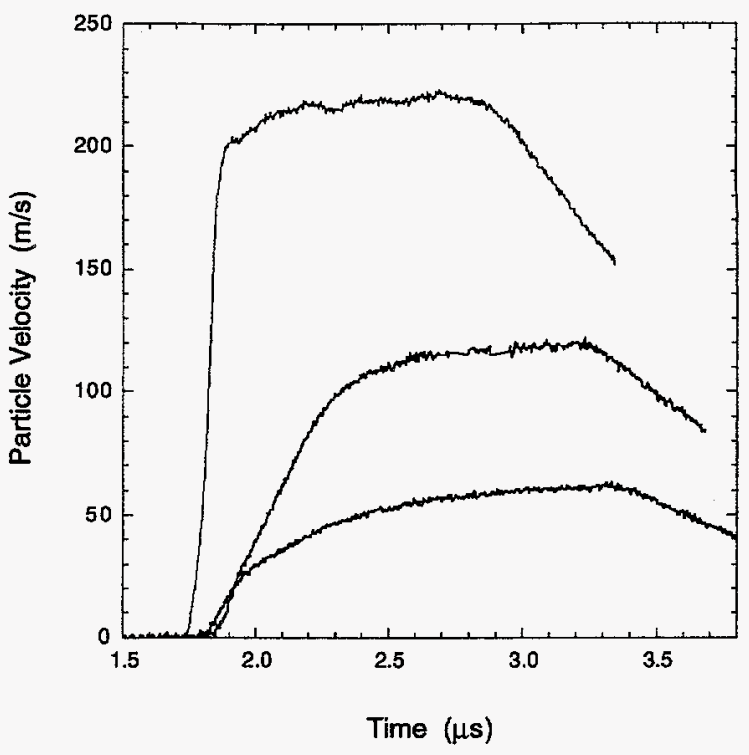

Figure 15: Experimental wave profiles in PBX 9501 at $0.30,0.56$, and $1.20 \mathrm{GPa}$. The magnetic gauges are at about $5.3 \mathrm{~mm}$ depth. The profiles are from experiments 1116, 1049, and 1058.

$580 \mathrm{MPa}$. The corresponding yield stresses are 54 and 66 MPa. The results for experiment 1042 at $600 \mathrm{MPa}$ using material that was ram-pressed from another lot has the largest Hugoniot elastic limit by a significant amount. It had a density of $1.835 \mathrm{~g} / \mathrm{cm}^{3}$.

For comparison, a Hugoniot elastic limit of $140 \mathrm{MPa}$ was measured in Composition B. ${ }^{11}, 12$ A very different, ramp-like precursor was observed for PBX 9502. ${ }^{13}$ The longitudinal stress value at the end of the ramp was 73 MPa. Chhabildas and Kipp measured the maximum shear stress in PBX 9404 using pressure-shear impact loading. ${ }^{14}$ Their result was $40 \mathrm{MPa}$. The yield stress is twice that, $80 \mathrm{MPa}$. From Vickers hardness tests a value of $66 \mathrm{MPa}$ was given for the flow stress for HMX by Mohan, Bhasu, and Field ${ }^{15}$ giving a value of $132 \mathrm{MPa}$ for $\mathrm{Y}$.

It is interesting to note that the threshold velocity for explosion in the spigot test or the Steven test corresponds to about $100 \mathrm{MPa}$ in PBX 9501 in the center after impact, close to the Hugoniot elastic limit. The threshold velocity may be correlated to the threshold for inelastic, irreversible, dissipative deformation. 
Table 4: PBX 9501 Hugoniot Elastic Limit and Yield Stress

\begin{tabular}{|c|c|c|c|c|c|c|}
\hline \multirow[b]{2}{*}{$\begin{array}{l}\text { Shot } \\
\text { num. }{ }^{a}\end{array}$} & \multicolumn{2}{|c|}{ Hugoniot elastic limit } & \multirow[b]{2}{*}{$\begin{array}{c}\text { Yield } \\
\text { stress } \\
(\mathrm{MPa})\end{array}$} & \multirow[b]{2}{*}{$\begin{array}{c}U_{0}^{e l} \\
(\mathrm{~mm} / \mu \mathrm{s})\end{array}$} & \multirow[b]{2}{*}{$\begin{array}{c}U_{1 / 2}^{e l} \\
(\mathrm{~mm} / \mu \mathrm{s})\end{array}$} & \multirow[b]{2}{*}{$\begin{array}{c}\text { Total rise } \\
\text { time } \\
\text { (ns) }\end{array}$} \\
\hline & $\begin{array}{c}\text { Particle } \\
\text { velocity } \\
(\mathrm{m} / \mathrm{s})\end{array}$ & $\begin{array}{l}\text { Stress } \\
(\mathrm{MPa})\end{array}$ & & & & \\
\hline $1071^{b}$ & 26 & 126 & 55 & 2.73 & 2.66 & 160 \\
\hline 1072 & 22 & 113 & 50 & 2.90 & 2.82 & 160 \\
\hline 1070 & 25 & 129 & 57 & 2.87 & 2.82 & 150 \\
\hline 1049 & 27 & 140 & 62 & 2.90 & 2.85 & 90 \\
\hline 1073 & 31 & 161 & 71 & 2.94 & 2.84 & 140 \\
\hline $1042^{c}$ & 41 & 219 & 96 & 3.00 & 2.91 & 75 \\
\hline
\end{tabular}

${ }^{a}$ The first three experiments had impact stresses around $300 \mathrm{MPa}$, and the last three around $600 \mathrm{MPa}$. Experiments 1072 and 1073 had samples $8 \mathrm{~mm}$ thick.

${ }^{b}$ In this experiment the rise time on the stirrup gauge on the impact face had a rise time of $120 \mathrm{~ns}$.

${ }^{c}$ The sample in this experiment was ram-pressed from another lot.

\section{F. PBX 9501 Strength vs Strain Rate}

Using Instron and Hopkinson bar instrumentation Los Alamos National Laboratory workers have measured the ultimate compressive strength on the same lot of PBX 9501 pressed to the same density by the same technique. ${ }^{6,16}$ The ultimate compressive strength is the maximum compressive stress achieved. Yield stresses are proportional to and less than the ultimate compressive strengths. The results are displayed in Fig. 16.

Earlier measurements of PBX 9501 ultimate compressive strength are listed in Ref. 5 for several temperatures. There is strong temperature dependence of strength. The strain rate is not specified but may have been $0.00083 \mathrm{~s}^{-1}$. The density is $1.844 \mathrm{~g} / \mathrm{cm}^{3}$. At $24^{\circ} \mathrm{C}$ the ultimate compressive strength is given as $7.86 \mathrm{MPa}$. This value is slightly lower than values for the current material. In other earlier work on another lot of PBX 9501 reported in Dobratz's compendium, ${ }^{17}$ the ultimate compressive strength in Instron tests is about $6 \mathrm{MPa}$ at a strain rate of $10^{-5} \mathrm{~s}^{-1}, 33$ $\mathrm{MPa}$ at $750 \mathrm{~s}^{-1}$, and $43 \mathrm{MPa}$ at $10^{3} \mathrm{~s}^{-1}$.

There is significant strain-rate dependence of the yield stress. The state of strain may also be important. Mechan- ical failure in PBX 9501 and other PBXs at low strain rates has been studied in detail by Wiegand. ${ }^{18}$

\section{G. Wave Profiles in PBX 9501 from 1.6 to 2 GPa}

There is evidence of initiation for impact stresses from 1.6 to $2 \mathrm{GPa}$. The experiments were 1053 and 1062 at 1.56 and $1.61 \mathrm{GPa}$ and $5 \mathrm{~mm}$ sample thickness, 1124 at $1.57 \mathrm{GPa}$ and $10.0 \mathrm{~mm}, 1125$ at $1.80 \mathrm{GPa}$ and $4.96 \mathrm{~mm}$, and 1081 at $1.96 \mathrm{GPa}$ and $4.54 \mathrm{~mm}$. A summary of the profiles obtained is displayed in Fig. 17. All impactors were z-cut quartz. They were $57.2 \mathrm{~mm}$ in diameter and partially supported laterally with epoxy on all shots except 1053 and 1062 where they were $50.8 \mathrm{~mm}$ in diameter and flush-mounted in the aluminum projectile with lateral aluminum support. The experiments were one-dimensional (uniaxial strain) at the mirror center until in the neighborhood of $5 \mu$ s. The quartz impactors were backed by foam with a density of about $0.48 \mathrm{~g} / \mathrm{cm}^{3}$ and a thickness of 5 or $6 \mathrm{~mm}$, except for experiments 1053 and 1062 that were backed by $8 \mathrm{~mm}$ of PMMA. The results represent delayed initiation. As such, they should provide good test data for numerical modelling of hazards tests that are performed at lower stresses with longer delay times for initiation and 


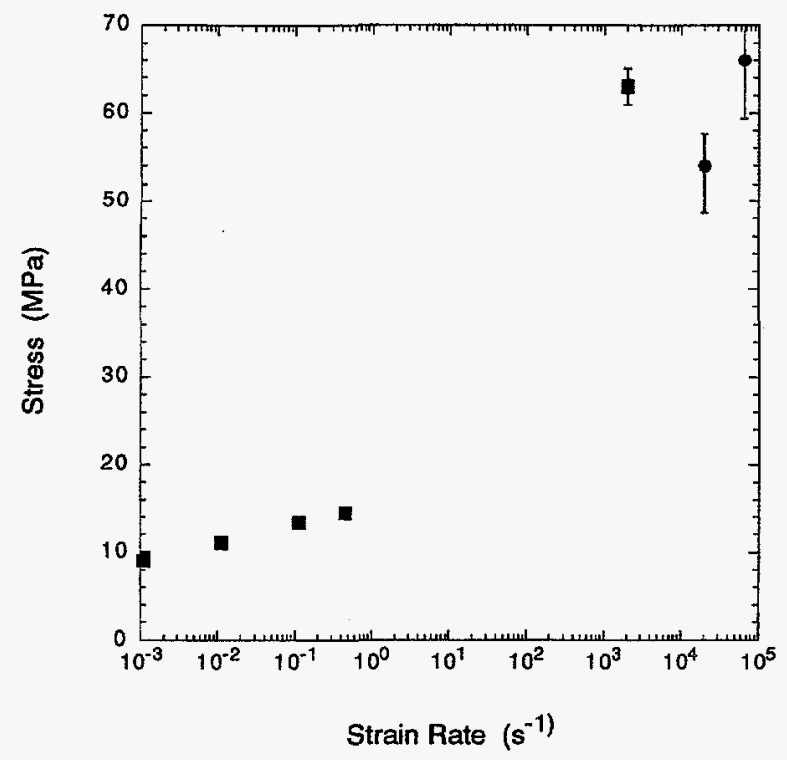

Figure 16: Ultimate compressive strengths and yield stresses vs strain rate for PBX 9501 . The square blue points are ultimate compressive strengths from Instron tests at about $27^{\circ} \mathrm{C}$. Error bars are less than $0.5 \mathrm{MPa}$, smaller than the points. Specimens were $9.5 \mathrm{~mm}$ diameter by $19 \mathrm{~mm}$ long. The ends were lubricated. The red square is an ultimate compressive strength from Hopkinson bar tests at about $16^{\circ} \mathrm{C}$. Samples were $6.35 \mathrm{~mm}$ in diameter and $3.18 \mathrm{~mm}$ long. The black circles are yield stresses computed from Hugoniot elastic limits in plate impact tests at about $23^{\circ} \mathrm{C}$. All samples are from the same lot and hydropressed to the same density $1.827 \mathrm{~g} / \mathrm{cm}^{3}$.

for modelling of the hazard scenarios themselves.

At the highest impact stress of $1.96 \mathrm{GPa}$, experiment 1081, (upper black curve in Fig. 17) strong initiation occurs during a shock pulse of about $2 \mu$ s duration; the impactor was $6.37 \mathrm{~mm}$ thick. The initial particle velocity at the PMMA window is calculated to be $402 \mathrm{~m} / \mathrm{s}$ by MACRAME with an interface longitudinal stress of 1.54 GPa. The exothermic decomposition leading to initiation is made evident by the rising particle velocity and pressure in the wave profile from the VISAR record for a sample $4.538 \mathrm{~mm}$ thick. Strong decomposition begins about 0.8 $\mu$ s after shock arrival, well before the rarefaction arrives from the back of the impactor. The Pop plots in LASL Explosive Property Data ${ }^{5}$ give a run distance of $21.2 \mathrm{~mm}$ and time to detonation of $6.45 \mu \mathrm{s}$ for a density of 1.833 $\mathrm{g} / \mathrm{cm}^{3}$. For a density of $1.844 \mathrm{~g} / \mathrm{cm}^{3}$ it gives a run distance of $36.9 \mathrm{~mm}$ and a time to detonation of $10.5 \mu \mathrm{s}$. The

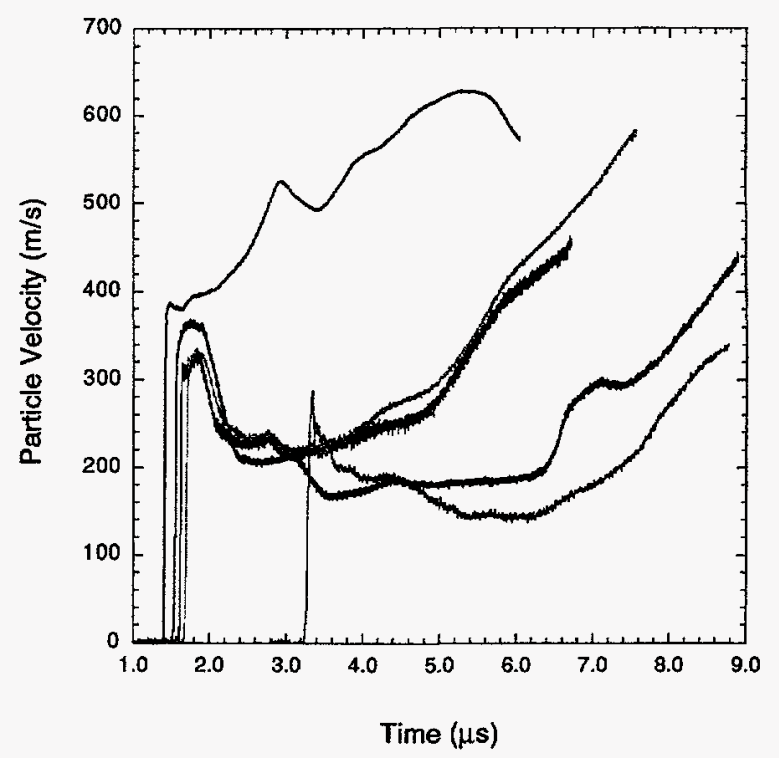

Figure 17: Experimental wave profile records in PBX 9501 at 1.6 to $2 \mathrm{GPa}$ at the PBX 9501/PMMA interface using VISAR instrumentation. The PBX 9501 samples are about 4.5 to $5 \mathrm{~mm}$ thick except for one at $10 \mathrm{~mm}$.

run distance for the density $1.823 \mathrm{~g} / \mathrm{cm}^{3}$ of the sample used in experiment 1081 will be shorter than, but close to that for $1.833 \mathrm{~g} / \mathrm{cm}^{3}$ material.

Using a theoretical maximum density $1.860 \mathrm{~g} / \mathrm{cm}^{3}$ the porosity is $2.0 \%$ for $1.823 \mathrm{~g} / \mathrm{cm}^{3}, 1.8 \%$ for $1.827 \mathrm{~g} / \mathrm{cm}^{3}$, $1.5 \%$ for $1.833 \mathrm{~g} / \mathrm{cm}^{3}$, and $0.9 \%$ for $1.844 \mathrm{~g} / \mathrm{cm}^{3}$. The $1.844 \mathrm{~g} / \mathrm{cm}^{3}$ material is close to dead pressed; that is, the concentration of hot spots is so low that it may be initiating more like a homogeneous explosive. The run distance and time to detonation for $1.827 \mathrm{~g} / \mathrm{cm}^{3}$ material should be somewhat shorter than for $1.833 \mathrm{~g} / \mathrm{cm}^{3}$ PBX 9501 .

The next lower experiment, 1125, had an impact stress of $1.80 \mathrm{GPa}$ (red curve in Fig. 17). Its impactor was $3.00 \mathrm{~mm}$ thick. The initial particle velocity at the PMMA window is calculated to be $363 \mathrm{~m} / \mathrm{s}$ by MACRAME with an interface longitudinal stress of $1.42 \mathrm{GPa}$. There is little evidence of initiation until late times with this lower impact stress and shorter pulse. The reduction in stress by the rarefaction has a significant effect on the initiation progress.

Two nearly identical experiments, 1053 and 1062, were performed at about $1.60 \mathrm{GPa}$ (blue and orange curves in Fig. 17). The impactor velocities were 0.380 and 0.381 $\mathrm{mm} / \mu \mathrm{s}$, respectively. The impactors were $2.56 \mathrm{~mm}$ thick 
backed by $8 \mathrm{~mm}$ of PMMA. The initial particle velocity at the PMMA window is calculated to be $333 \mathrm{~m} / \mathrm{s}$ by MACRAME with an interface longitudinal stress of 1.30 GPa. The two interface profiles agree well with each other to $4 \mu \mathrm{s}$ and within $10 \%$ to $6.6 \mu \mathrm{s}$. The profiles show evidence of late initiation as the particle velocity increases. Another experiment 1124 was executed at $1.57 \mathrm{GPa}$ (lower black curve in Fig. 17). The sample was $10 \mathrm{~mm}$ thick, and the impactor was $3 \mathrm{~mm}$ thick backed by foam. The purpose was to see the effect of a longer distance of propagation on the initiation. The profile shows that the rarefaction has overtaken the shock front and attenuated the wave. Furthermore, the levels following the leading part of the rarefaction are lower than on the experiments with samples $5 \mathrm{~mm}$ thick. This is due to the lower particle velocities and stresses generated by the rarefaction from the interface between the quartz and the backing material. The PMMA backing material in the $5 \mathrm{~mm}$ experiments has higher impedance than the foam, and leads to higher particle velocities and stresses behind the leading rarefaction. The fact that the particle velocity begins to increase at later times with the $10 \mathrm{~mm}$ thick sample than the $5 \mathrm{~mm}$ ones could mean that the initiation begins at the impact face, and has farther to travel to reach PBX 9501/PMMA measurement interface. Also, the lower stresses and particle velocities behind the lead rarefaction could cause a longer induction time.

In most of these experimental profiles the profiles are of interest to late times. In hazard situations the onset of initiation of explosion or detonation may occur after a considerable delay from the time of the initial mechanical stimulus. The experiments presented here are completely one-dimensional at the measurement interface center for about $5 \mu$ s after impact. Two-dimensional numerical calculations would be necessary to determine the deviation from one dimensionality out to $9 \mu \mathrm{s}$. Furthermore, the effect of two-dimensional flow on the VISAR signal is not known. However, we had a u-t profile at $1.2 \mathrm{GPa}$ where we were fairly certain that initiation was not taking place. If our memory is correct there was residual explosive in the target chamber after the shot, no soot. Based on these considerations it seemed worthwhile to compare the exper- iments to one-dimensional calculations of the $u$-t profiles at the measurement interface using the MACRAME characteristics code.

The comparison for experiment 1054 at $1.2 \mathrm{GPa}$ is displayed in Fig. 18. There is rough agreement out to $8 \mu \mathrm{s}$. The experimental profile does not reach the maximum particle velocity because at $1.2 \mathrm{GPa}$ and $5 \mathrm{~mm}$ propagation distance, PBX 9501 does not reach the final state until several hundred nanoseconds behind the main compressive wave (see Fig. 14). The rarefaction overtakes it before the final state is reached. MACRAME is a hydrodynamic characteristics code. This means the shocks are discontinuities and the lead rarefaction moves at bulk sound speed. In a composite material with strength such as PBX 9501 the shock is dispersed, and the lead rarefaction moves at longitudinal sound speed, faster than the bulk sound speed. This explains some of the differences between the computed and measured profiles. Still, the agreement in particle velocity levels behind the leading rarefaction is good out to almost $8 \mu \mathrm{s}$. The jump in particle velocity in both profiles at about $7.5 \mu \mathrm{s}$ is noteworthy. This jump is caused by the shock from the aluminum projectile body that supports the $8 \mathrm{~mm}$ thick PMMA disc that is behind the quartz impactor. This shock will appear for the impactors backed by PMMA but not for those backed by foam because of higher PMMA wave speeds. The overall experience from the VISAR experiments is that the records may have validity up to about $9 \mu \mathrm{s}$, at least for z-cut quartz impactors no more than $3 \mathrm{~mm}$ thick.

All the materials except $\mathrm{z}$-cut quartz have wave speeds around $3 \mathrm{~mm} / \mu \mathrm{s}$. So, for the samples with $25.4 \mathrm{~mm}$ radius the lateral rarefactions should not reach the center until after $8 \mu \mathrm{s}$. The $\mathrm{z}$-cut quartz has velocities over 6 $\mathrm{mm} / \mu \mathrm{s}$. So, if it were isolated the rarefactions could reach the center of it in about $4 \mu \mathrm{s}$. However, for thin impactors in the experiments there are reverberations in it from the surrounding PBX 9501 and foam. These cause drag on the lateral effects and minimize them until a much later time after impact.

Based on these observations at $1.2 \mathrm{GPa}$ it is worthwhile to make the same sort of comparison for the experiments 


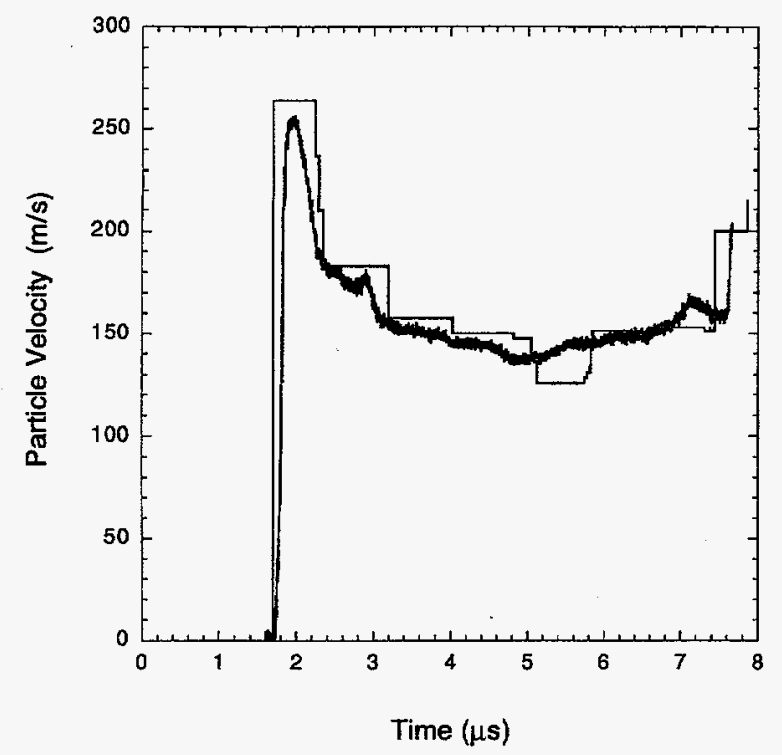

Figure 18: Comparison of the wave profile for experiment 1054 in PBX 9501 at $1.2 \mathrm{GPa}$ at the PBX 9501/PMMA interface with a calculation by the MACRAME characteristics code. The PBX 9501 sample is $5.04 \mathrm{~mm}$ thick. The z-cut quartz impactor was $2.55 \mathrm{~mm}$ thick and backed by $8 \mathrm{~mm}$ of PMMA.

at higher impact stresses. The result for experiment 1053 at $1.56 \mathrm{GPa}$ and $5.02 \mathrm{~mm}$ is shown in Fig. 19. The initiation becomes discernible at about $3 \mu$ s and accelerates at about $5 \mu \mathrm{s}$. This is within the one-dimensional time for the experiment. Without initiation the calculational results imply that the interface is held at 0.6 to $0.8 \mathrm{GPa}$ when the quartz impactor is backed by PMMA.

For experiment 1124 at $1.57 \mathrm{GPa}$ and $10.02 \mathrm{~mm}$ the comparison is shown in Fig. 20. This comparison shows clearly the attenuation of the thin shock pulse in the experiment with wave propagation distance. The wave front is attenuated by about $12 \%$. The impactor is backed by low impedance foam. The calculated profile shows that the particle velocity drops continually with foam backing as waves reverberate across the impactor, in contrast to PMMA backing. This same behavior of more rapid and continuous reduction in pressure will have taken place at the PBX 9501 impact face. At about $4 \mu$ s the calculated interface pressure drops to about $0.65 \mathrm{GPa}$ and at about $5 \mu \mathrm{s}$ to about $0.4 \mathrm{GPa}$. The experimental profile begins to stay at higher particle velocities than the calculated profile at about $5 \mu$ s and shows strong apparent initiation at

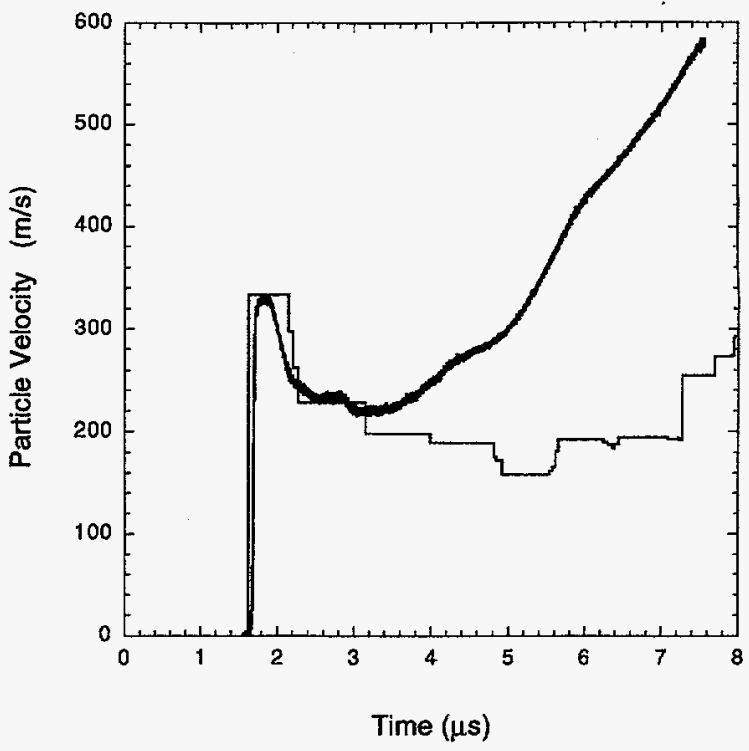

Figure 19: Comparison of the experimental wave profile 1053 in PBX 9501 at $1.56 \mathrm{GPa}$ at the PBX 9501/PMMA interface with a calculation by the MACRAME characteristics code. The PBX 9501 sample is $5.02 \mathrm{~mm}$ thick. The z-cut quartz impactor is $2.57 \mathrm{~mm}$ thick and backed by $8 \mathrm{~mm}$ of PMMA.

about $6 \mu \mathrm{s}$.

The comparison for experiment 1125 at $1.80 \mathrm{GPa}$ is displayed in Fig. 21. The particle velocity and pressure drop rapidly as waves in the impactor reverberate between the PBX 9501 and the foam. There may be evidence of initiation beginning at $2.5 \mu \mathrm{s}$ and clear evidence after $3 \mu \mathrm{s}$. The computed interface pressure drops to about $0.72 \mathrm{GPa}$ at $2.5 \mu \mathrm{s}$ and to about $0.45 \mathrm{GPa}$ at $3.5 \mu \mathrm{s}$. At $5.2 \mu \mathrm{s}$ it drops to $0.2 \mathrm{GPa}$; this is from the reverberation of the initial shock in the sample. At $6.2 \mu$ s the pressure increases to $0.35 \mathrm{GPa}$; this is from the reverberation of the initial rarefaction in the sample. The bump and rapid rise in particle velocity in the measured profile begins at about this time.

In order to make a more convincing case for the profiles, it was decided to perform an experiment with an inert sample holding the experimental geometry constant. Kel-F (polychlorotrifluoroethylene) plastic was used for the sample. It has a $P_{x}-u_{p}$ Hugoniot very close to that of PBX 9501. The impactor was z-cut quartz $3.015 \mathrm{~mm}$ thick backed by $5 \mathrm{~mm}$ of foam. The Kel-F sample was 5.01 $\mathrm{mm}$ thick. These are a close match to experiment 1125 


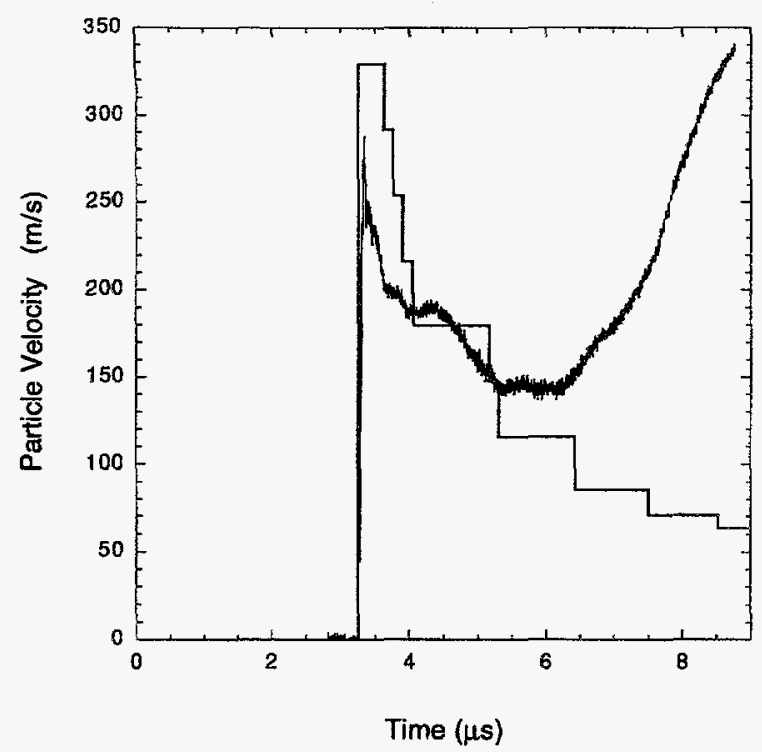

Figure 20: Comparison of the experimental wave profile 1124 in PBX 9501 at $1.57 \mathrm{GPa}$ at the PBX 9501/PMMA interface with a calculation by the MACRAME characteristics code. The PBX 9501 sample is $10.02 \mathrm{~mm}$ thick. The z-cut quartz impactor was $3.010 \mathrm{~mm}$ thick and backed by 5 $\mathrm{mm}$ of foam.

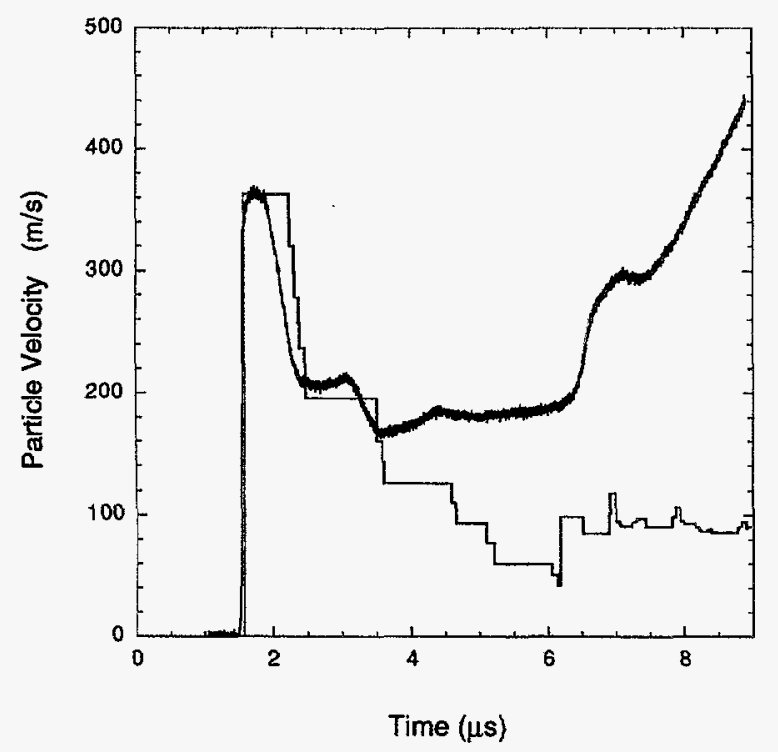

Figure 21: Comparison of the experimental wave profile 1125 in PBX 9501 at $1.80 \mathrm{GPa}$ at the PBX 9501/PMMA interface with a calculation by the MACRAME characteristics code. The PBX 9501 sample is $4.96 \mathrm{~mm}$ thick. The z-cut quartz impactor was $3.007 \mathrm{~mm}$ thick and backed by 5 $\mathrm{mm}$ of foam. with PBX 9501. The impactor velocity was $0.403 \mathrm{~mm} / \mu \mathrm{s}$ for an impact stress of $1.66 \mathrm{GPa}$ and particle velocity of $0.307 \mathrm{~mm} / \mu \mathrm{s}$. The experimental results and comparison to MACRAME calculation are presented in Fig. 22. The experimental profile for the Kel-F polymer is dispersed at the top of the compressive wave. This allows the rarefaction to overtake and attenuate it. The agreement for the thin pulse is good out to $7.5 \mu \mathrm{s}$. The MACRAME $\mathrm{x}$-t results show the arrival of the reverberation of the rarefaction wave in the sample by this time. Wave interactions at late times are complex and may get smoothed out. This sort of behavior is manifest in Fig. 18 at $5.5 \mu$ s. Wave speeds in Kel-F are somewhat slower than in PBX 9501 so that reverberation effects appear at later times in Kel-F. Overall one can conclude that the longitudinal particle velocity at the rear of the sample is not significantly affected by lateral flow in the first $8 \mu$ s after impact when thin z-cut quartz impactors are used.

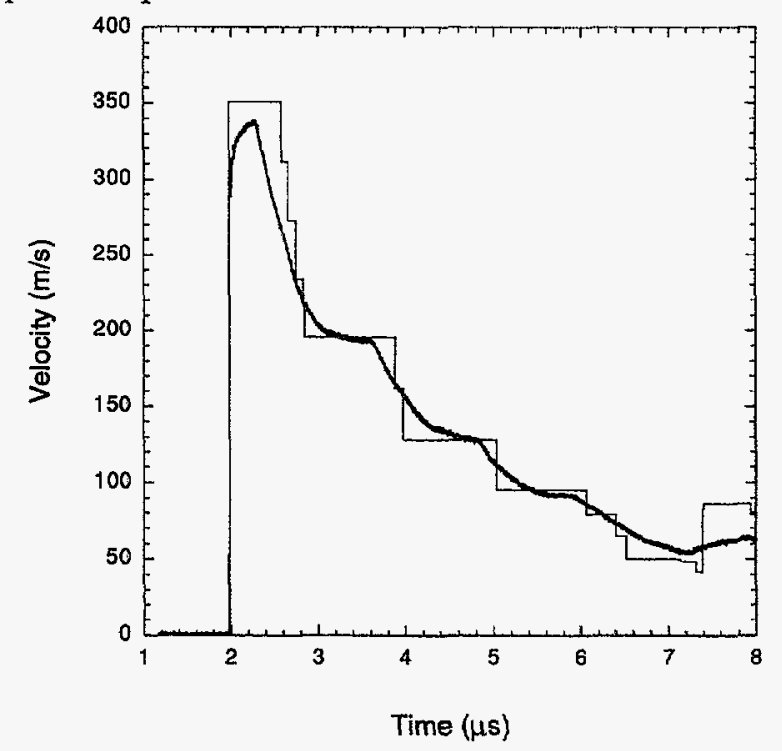

Figure 22: Comparison of the experimental wave profile 1136 in Kel-F at $1.66 \mathrm{GPa}$ at the Kel-F/PMMA interface with a calculation by the MACRAME characteristics code. The Kel-F sample is $5.01 \mathrm{~mm}$ thick. The z-cut quartz impactor was $3.015 \mathrm{~mm}$ thick and backed by $5 \mathrm{~mm}$ of foam.

Fig. 23 shows the comparison between the MACRAME calculation and the data at $1.96 \mathrm{GPa}$ for experiment 1081 . This experiment had a z-cut quartz impactor $6.37 \mathrm{~mm}$ thick providing a shock pulse over twice as long as for the other experiments in this set. At this stress the initiation is 


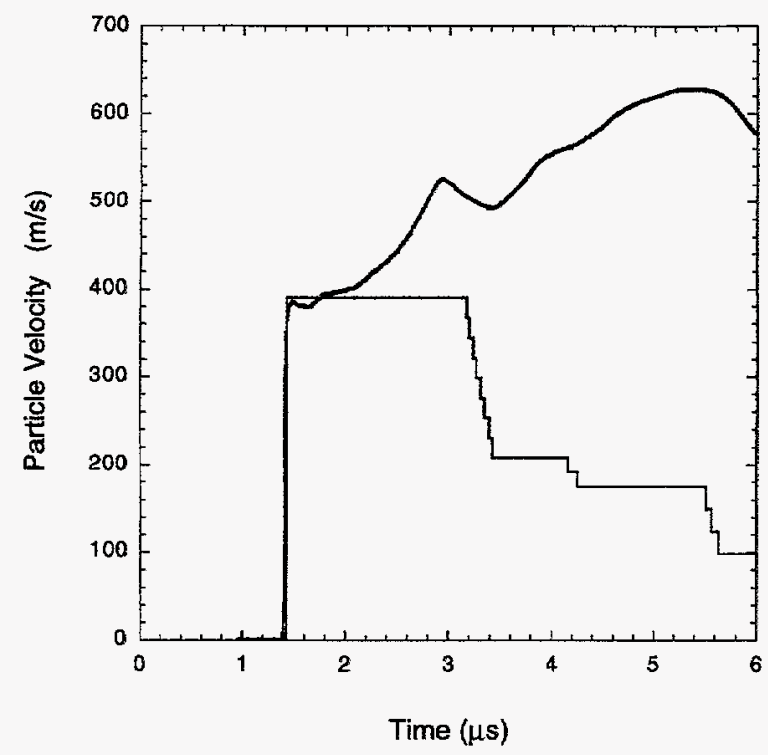

Figure 23: Comparison of the wave profile for experiment 1081 in PBX 9501 at $1.96 \mathrm{GPa}$ at the PBX 9501/PMMA interface with a calculation by the MACRAME characteristics code. The PBX 9501 sample is $4.54 \mathrm{~mm}$ thick. Measured sample density was $1.823 \mathrm{~g} / \mathrm{cm}^{3}$. The z-cut quartz impactor was $6.37 \mathrm{~mm}$ thick and backed by $6 \mathrm{~mm}$ of foam.

prompt within $0.8 \mu$ s of the shock. The successive particle velocity decreases in the calculation are seen in the measured profile superimposed on the particle velocity increase with time due to initiation. In the calculation the initial shock pressure at the interface is $1.54 \mathrm{GPa}$. After $3 \mu \mathrm{s}$ it drops to $0.78 \mathrm{GPa}$, after $4 \mu$ s to $0.64 \mathrm{GPa}$, and after $5.5 \mu \mathrm{s}$ to $0.35 \mathrm{GPa}$. The behavior of the measured profile after 6 $\mu \mathrm{s}$ is peculiar in dropping down and then going up again. The reverberation of the rarefaction through the sample arrives at the interface at about $6.3 \mu \mathrm{s}$ in the calculation. While there is a small dip in the MACRAME profile at about this time, the graph is terminated at $6 \mu$ s due to the increased effect of lateral rarefactions in the thick quartz impactor.

\section{H. PBX 9501 Rise Times and Strain Rates}

The rise times of the profiles in the experiments in PBX 9501 were measured. The rise time was taken as the rise time from $10 \%$ to $90 \%$ of the total signal rise. Since the approach to final state is so gradual at low stresses, it is difficult to pick off the precise time at times closer to the final state than $90 \%$. The values are recorded in Table 5 and displayed in Fig. 24. One notes that at 0.3 and $0.6 \mathrm{GPa}$ impact stresses, the rise times increase with propagation distance out to about $8 \mathrm{~mm}$. It appears that the waves become steady after 7 to $8 \mathrm{~mm}$ of propagation distance at these impact stresses. At $1.2 \mathrm{GPa}$ the rise time increases from 60 to about $100 \mathrm{~ns}$ between 2 and $4 \mathrm{~mm}$.

It is worth noting that the plastic wave in HMX single crystals $3 \mathrm{~mm}$ thick impacted at $1.4 \mathrm{GPa}$ has a rise time of about 122 ns. In pentaerythritol tetranitrate (PETN) crystals unsteady plastic waves were observed. ${ }^{19}$ Therefore, some of the dispersed, unsteady wave behavior seen in PBX 9501 may be inherent in the HMX.

The behavior of decreasing rise time with increasing impact stress has been noted before as the typical response to shocks. Swegle and Grady noted that for metals and oxides that the peak strain rate in the shock was consistent with a power-law relation between the peak strain rate and the shock stress; 20 the peak strain rate for the total strain varies as the fourth power of the shock stress. They obtained the peak strain rate in the shock profile by numerically differentiating the measured profile.

For comparing the PBX 9501 data to this relation, the strain rate in the wave front was taken as the total strain divided by the 10 to $90 \%$ rise time at sample thicknesses where the wave had become steady. The comparison is shown in Fig. 25. The line is 0.0395 times the strain rate to the one-fourth power. The data for PBX 9501 agree with the power law except at $0.3 \mathrm{GPa}$. Swegle and Grady had also noted this sort of deviation when the shock stress is not much larger than the elastic limit.

\section{Wave Speed as a Function of Particle Speed through the Unsteady Wave}

A steady wave is one whose profile does not change as it propagates between two Lagrangian positions in the material. From the plot for rise time vs wave propagation distance (Fig. 24), the increase in rise time with propagation distance shows that the wave is not steady at low impact stresses and short distances of propagation. The varying profile can be expressed as the variation in wave velocity 
Table 5: Rise Times for PBX 9501 Waves

\begin{tabular}{|c|c|c|c|}
\hline $\begin{array}{l}\text { Shot } \\
\text { num. }\end{array}$ & $\begin{array}{c}\text { Thick- } \\
\text { ness } \\
(\mathrm{mm})\end{array}$ & $\begin{array}{c}\mathrm{P}_{x} \\
(\mathrm{GPa})\end{array}$ & $\begin{array}{r}\text { Rise } \\
\text { time }^{a} \\
\text { (ns) }\end{array}$ \\
\hline 1116 & 1.322 & 0.303 & 400 \\
\hline$"$ & 2.318 & 0.303 & - \\
\hline$"$ & 3.298 & 0.303 & 740 \\
\hline$"$ & 4.27 & 0.303 & 900 \\
\hline$"$ & 5.274 & 0.303 & 1080 \\
\hline 1070 & 5.415 & 0.345 & 1030 \\
\hline 1071 & 5.405 & 0.307 & 1080 \\
\hline 1072 & 7.993 & 0.310 & 1330 \\
\hline 1061 & 7.993 & 0.341 & 1330 \\
\hline 1049 & 1.394 & 0.560 & 228 \\
\hline$"$ & 2.412 & 0.560 & 266 \\
\hline$"$ & 3.405 & 0.560 & 372 \\
\hline$"$ & 4.374 & 0.560 & 406 \\
\hline$"$ & 5.370 & 0.560 & 496 \\
\hline 1117 & 5.39 & 0.582 & 502 \\
\hline 1073 & 7.976 & 0.579 & 660 \\
\hline 1060 & 10.018 & 0.598 & 658 \\
\hline 1058 & 1.37 & 1.18 & 62 \\
\hline$"$ & 2.36 & 1.18 & 72 \\
\hline$"$ & 3.36 & 1.18 & 97 \\
\hline$"$ & 4.33 & 1.18 & 110 \\
\hline$"$ & 5.33 & 1.18 & 106 \\
\hline 1054 & 5.04 & 1.20 & 86 \\
\hline 1053 & 5.016 & 1.56 & 28 \\
\hline 1062 & 4.982 & 1.61 & 18 \\
\hline 1124 & 10.015 & 1.57 & 50 \\
\hline 1125 & 4.956 & 1.80 & 35 \\
\hline 1081 & 4.538 & 1.96 & 17 \\
\hline
\end{tabular}

${ }^{a^{a}}$ The rise times were measured from 10 to $90 \%$ of the total particle velocity increase.

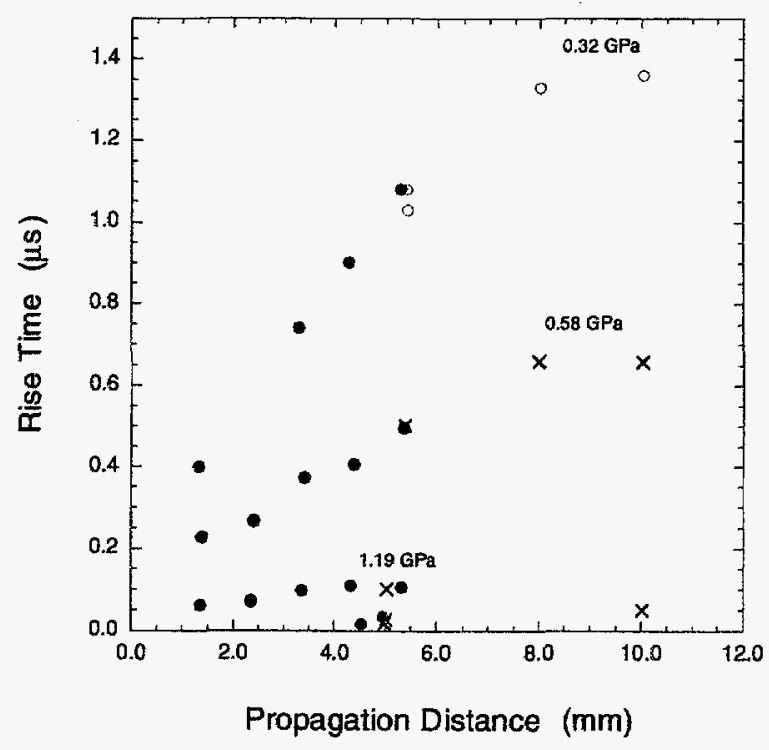

Figure 24: Compressive wave rise time vs wave propagation distance for several impact stress levels in PBX 9501. The black exes are near 1.6 $\mathrm{GPa}$, the orange circle near $1.8 \mathrm{GPa}$, and the green circle near $2 \mathrm{GPa}$.

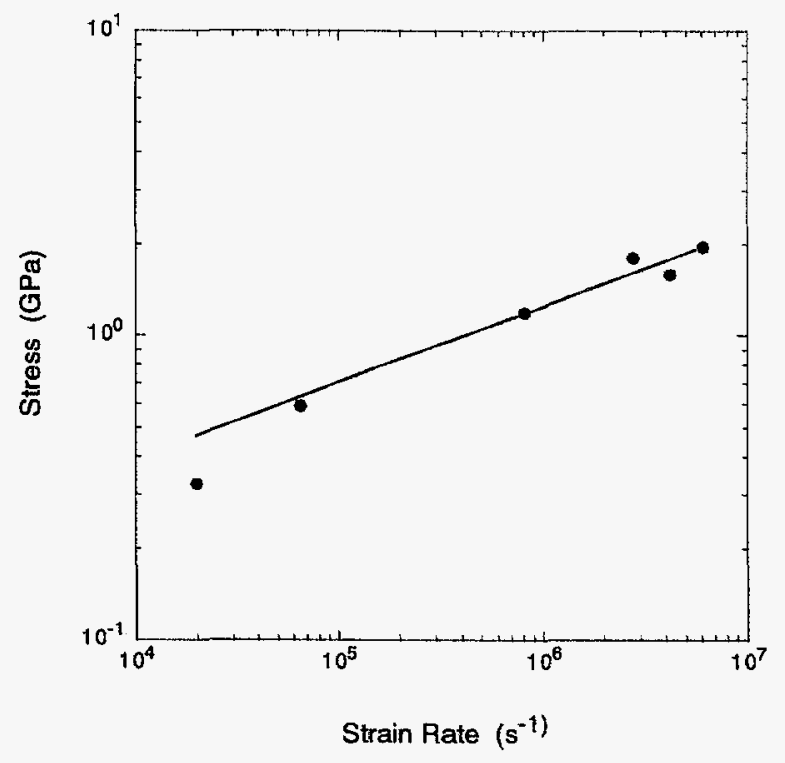

Figure 25: Comparison of the total strain rates of PBX 9501 for steady waves vs impact stress to the fourth power law. 
with particle velocity through the profile. The higher particle velocity components are traveling more slowly than the low velocity components; so the wave spreads. Two examples for experiments at 303 and $560 \mathrm{MPa}$ using data from wave profiles in Figs. 6 and 8 are given in Fig. 26.

The particle velocity profiles at given Lagrangian gauge positions can be used to find the phase velocities ${ }^{21}$

$$
C_{u}=\left.\frac{\partial h}{\partial t}\right|_{u}
$$

For compactness of notation and consistency with previous work, $u$ is used to denote longitudinal particle velocity and $\sigma$ to denote longitudinal stress in the direction of wave propagation. Using the phase velocity $C_{u}$, the volume and strain through the wave, along the loading path, can be obtained using

$$
d V=-\frac{d u}{\rho_{0} C_{u}(u)} .
$$

Independent stress-time $(\sigma-t)$ profiles are needed in order to obtain stress-strain curves at a given Lagrangian position $h$. The phase velocities at constant stress are defined as

$$
C_{\sigma}=\left.\frac{\partial h}{\partial t}\right|_{\sigma}
$$

The phase velocities $C_{\sigma}$ and $C_{u}$ are equal only for simple waves, steady waves or discontinuities. If they are approximately equal, then one may substitute $C_{u}$ for $C_{\sigma}$ in Eqn. 10

$$
d \sigma=\rho_{0} C_{\sigma} d u
$$

to calculate stresses through the wave.

In order to obtain the phase velocities $C_{u}$, the arrival times at each of the five gauges one mm apart for a given particle velocity were recorded. In general the five data points appeared to follow a straight line within the precision of the data. A linear fit to the data yielded a wave velocity at that particle velocity. A constant value of $C_{u}$ through the five Lagrangian positions (straight characteristics) defines a simple wave, in this case a nonisentropic simple wave. ${ }^{22}$ Therefore, the integrations for calculating $\mathrm{V}$ and $\sigma$ with time at a given Lagrangian position can be carried out.
At $303 \mathrm{MPa}$ the separation into elastic and inelastic wave regions is evident in Fig. 26. The elastic range below 0.025 $\mathrm{mm} / \mu \mathrm{s}$ yields a fit of $C_{u}(u)=2.81-5.94 u$. There is some wave dispersion even for the elastic wave. The inelastic range gives a fit of $C_{u}(u)=3.16-19.5 u$. A similar analysis can be applied to the release waves.

At $560 \mathrm{MPa}$ the resultant wave velocities as a function of the particle velocity through the wave appear to fall on a straight line. A fit to the data gives $C_{u}(u)=2.92-4.96 u$. Here the dispersion coefficient 4.96 is close to the elastic coefficient 5.94 at $303 \mathrm{MPa}$. The $C_{u}(u)$ data at $560 \mathrm{MPa}$ agree well with data obtained by Olinger and Hopson using manganin gauges. 11

While there is no strong nonlinearity in the wave arrival times at a given particle velocity between 1.3 and $5.3 \mathrm{~mm}$, the waves appear to become steady by $8 \mathrm{~mm}$ of wave propagation according to Fig. 24. For a steady wave $C_{u}(u)$ is a constant for all $u$; all parts of the wave are moving at the same velocity. In some way the transition from unsteady to steady must be made by all parts of the wave coming to a common velocity. In order to do a precise test for steadiness, it is necessary to perform an experiment to measure the in-material profile at two Lagrangian positions in the steady region. If the wave is steady the transit time between the two positions will be identical for all particle velocities. All states in the wave will lie on a Rayleigh line. One way for steadiness to be achieved is for the lower parts of the wave to slow down and the upper parts of the wave to speed up.

\section{J. Discussion of Experimental Errors}

For the $303 \mathrm{MPa}$ experiment just discussed, the intercept at zero particle velocity is $2.81 \mathrm{~mm} / \mu \mathrm{s}$. This is below the typical value for the initial elastic disturbance of about $2.90 \mathrm{~mm} / \mu$ s by about $3 \%$. It is low probably due to measurement error. It became apparent that it is significant that each successive gauge that is $1 \mathrm{~mm}$ deeper in the sample is also staggered sideways by $1.7 \mathrm{~mm}$ (Fig. 1). This makes the experiment like a wedge test in that one is really measuring the phase velocity along the oblique face. This makes the measurement of wave velocity susceptible 


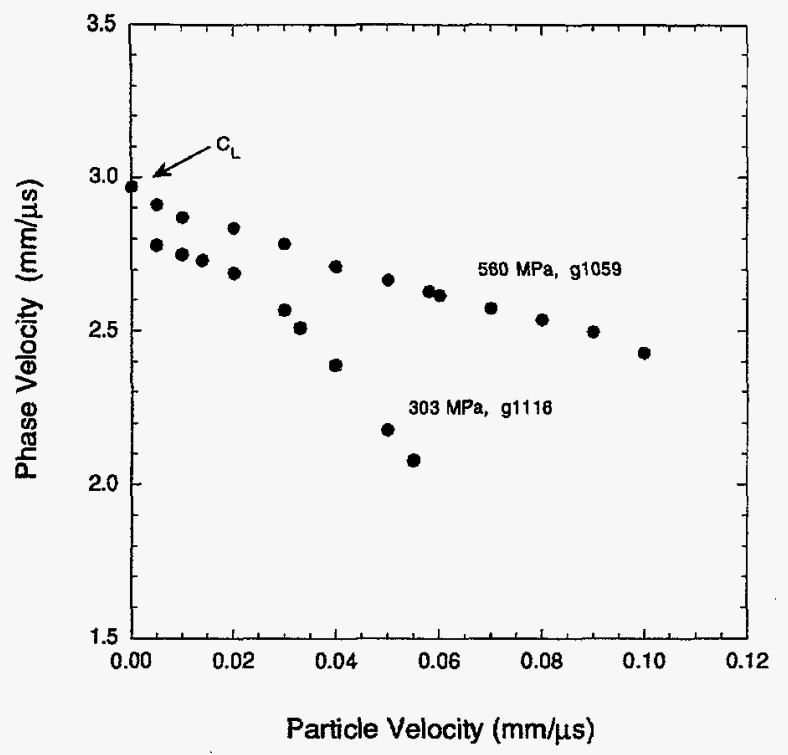

Figure 26: Compressive wave phase velocity $C_{u}$ as a function of particle velocity through the unsteady wave for two impact stresses.

to wave tilt errors, especially at low impactor velocities as were used to get to low impact stresses.

The tilt of the wave magnifies the tilt angle between the impactor and the sample surface by the ratio of the wave velocity to the impactor velocity. If the impactor velocity is $0.13 \mathrm{~mm} / \mu \mathrm{s}$ and the wave speed is $2.6 \mathrm{~mm} / \mu \mathrm{s}$ as is the case for $300 \mathrm{MPa}$ symmetric impact experiments, the ratio is 20 . The impactor tilt can be $1 \mathrm{mrad}$, where $1 \mathrm{deg}=17$ mrad, although we attempt to keep it to a fraction of a milliradian. For $1 \mathrm{mrad}$ of impact tilt the wave tilt is 20 mrad or $1.2 \mathrm{deg}$. The ratio of the actual velocity $U$ to the measured velocity $U_{M}$ is given by

$$
\frac{U}{U_{M}}=\left[1-\frac{\sin \alpha}{\sin \theta}\right]
$$

Here $\alpha$ is the impact tilt angle and $\theta$ is the angle that the gauge package is emplaced relative to the impact plane. For $\alpha$ of $20 \mathrm{mrad}$ and a $\theta$ of $30^{\circ}$ the ratio is 0.959 . This could explain the error in wave velocity in experiment 1116 at $300 \mathrm{MPa}$. It may also explain the high velocities abtained in experiment 1042.

A number of experiments were performed with two inplane stirrup gauges, one on the impact face and one embedded in the PBX 9501 at some depth. These measure impact time at the sample center directly and are not sus- ceptible to phase velocity errors due to tilt, as are the oblique embedded magnetic gauges, or the problems with PZT (lead zirconate titanate) pins at low velocities. Therefore, they should have the best precision for measuring transit times and wave speeds.

In VISAR experiments the transit time was measured by the time difference between impact time and onset of the VISAR signal at the explosive/PMMA interface. The time of impact was measured by two pins on opposite sides of a diameter $54 \mathrm{~mm}$ apart. The average of the times measured by the two pins should give the impact time at the sample center. In the experiments using stirrup gauges, 1070 to 1073 , the wave velocity was computed using the time difference between the impact gauge and the embedded gauge. In addition two PZT pins were used at the impact face in order to check the relative accuracy of the two methods. The samples were 5.4 to $8 \mathrm{~mm}$ thick. Impact velocities for the four experiments were $0.133,0.134$, 0.149 . and $0.148 \mathrm{~mm} / \mu \mathrm{s}$. The method using two stirrup gauges should be quite accurate. The PZT pin times have to be corrected for any deviation in position from the impact plane of the sample. The time uncertainty due to mechanical imprecision is magnified at low impactor velocities. The average difference in transit times between the two methods of measurement was $0.11 \mu \mathrm{s}$. This gives differences in wave velocity of about $5 \%$ and $0.14 \mathrm{~mm} / \mu \mathrm{s}$ for a wave speed of $2.6 \mathrm{~mm} / \mu \mathrm{s}$ in the thinnest sample. We have started using four pins so that some statistical averaging can be performed to improve the precision.

\section{K. Spall Experiments on PBX 9501 at $600 \mathrm{MPa}$}

An attempt was made to measure the spall strength of PBX 9501. This is the strength in tension at high strain rates. A tensile state is achieved by the collision of rarefactions in the sample after the initial compressive wave has passed through. For these experiments the sample rear surface is a free surface so that the compressive wave is reflected from it as a rarefaction to zero longitudinal stress. This rarefaction combines with the rarefaction from the back of the z-cut quartz impactor to generate tension.

Experiments 1082 and 1084 were performed in this way. 
The mirrors on the rear surface of the sample were $12 \mu \mathrm{m}$ thick aluminum foils. The resultant profile for experiment 1084 is shown in Fig. 27. A typical spall signal shows a reduction in particle velocity due to the rarefaction originating at the free surface. When spall occurs in the interior the tensile stresses drop to zero there. When this is communicated to the free surface, an increase in particle velocity is observed. The magnitude of this rebound is a measure of the spall strength. ${ }^{23}$ There is no detectable rebound in evidence in the experiments in PBX 9501. The inference is that the spall strength is zero within resolution. Apparently the $600 \mathrm{MPa}$ compressive wave comminutes the explosive sufficiently that it no longer has any strength; it acts like sand.

At low strain rates in Brazilian tests the tensile strength has been measured at $0.78 \pm 0.1 \mathrm{MPa}^{24}$ at a failure strain of 0.0039 . In Ref. 5 a value of $2.2 \mathrm{MPa}$ is given for ultimate tensile strength. This tells us that the explosive is generally weak in tension. These values are much lower than the compressive strength of PBX 9501.

Values this small might not have been resolvable in the spall experiments. One MPa is less than $0.2 \%$ of the compressive stress in the spall experiments. One can conclude that there is no large increase in tensile strength due to increased strain rate as there is in compressive tests.

Spall behavior of filled elastomers has been studied by Kanel' and coworkers. ${ }^{25}$ The samples had 75 wt $\%$ filler. A small but distinct spall signal was noted. The particle velocity continued to decrease with time after the spall signal. This was interpreted to mean that the elastomer maintained continuity and continued to stretch after the initial void nucleation. Coarse filler (160-200 $\mu \mathrm{m}$ particles) caused slower rise times and less deceleration than fine filler (20-50 $\mu \mathrm{m}$ particles).

\section{Additional Wave Profiles in PBX 9501}

For completeness, profiles from two embedded magnetic gauge, symmetric impact experiments are presented here. The first experiment of this type near $600 \mathrm{MPa}$ was performed on PBX 9501 that differed from the explosive used in the remaining experiments. It was from another lot,

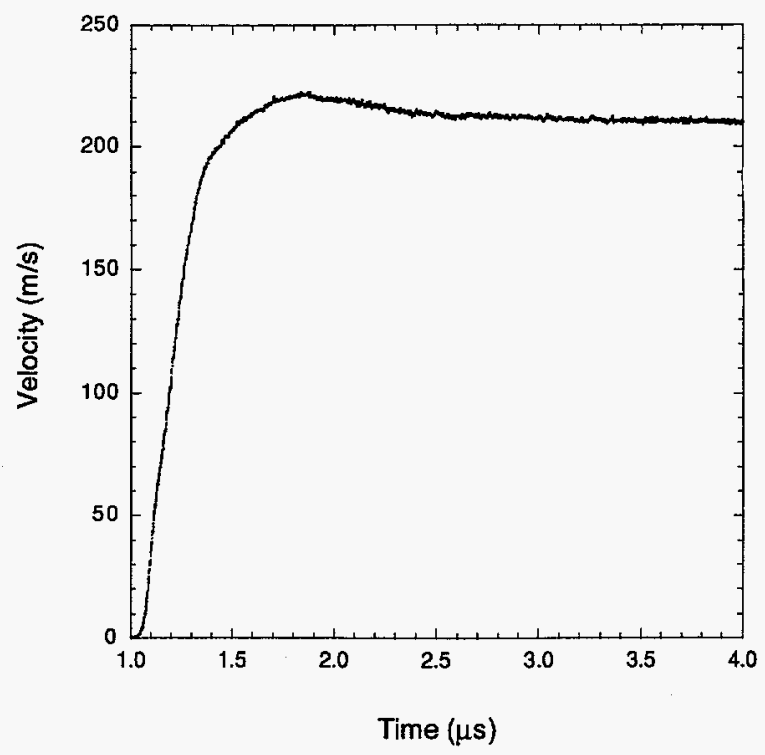

Figure 27: VISAR free-surface record of a spall experiment in PBX 9501 at $0.55 \mathrm{GPa}$, experiment 1084. The sample was $3.01 \mathrm{~mm}$ thick. The z-cut quartz impactor velocity was $0.153 \mathrm{~mm} / \mu \mathrm{s}$. The impactor was $3.028 \mathrm{~mm}$ thick.

was ram-pressed rather than hydrostatically pressed, and had a density of $1.835 \mathrm{~g} / \mathrm{cm}^{3}$ as opposed to $1.827 \pm 0.001$ $\mathrm{g} / \mathrm{cm}^{3}$. It has shorter rise times and a higher elastic limit (Fig. 28).

The first experiment at $300 \mathrm{MPa}$ was experiment 1059 . The final states measured were about $6 \%$ low (Fig. 29). The marked two-wave structure that it displayed was not repeated in subsequent experiments at this impact stress level. However, it made clear that an elastic wave and elastic limit existed. This was more subtle in subsequent experiments. One reason for the low precision in magnitude and profile in this experiment is that the mating surfaces of the explosive where the gauge is emplaced were poorly machined. The surfaces were rough and not as flat as is desirable.

\section{EXPERIMENTS ON THE COMPONENTS OF PBX 9501}

Numerical computation has advanced to a stage that wave propagation in a composite can be computed on a heterogeneous matrix of the components. Therefore, it is worthwhile to measure the plate impact response of the 


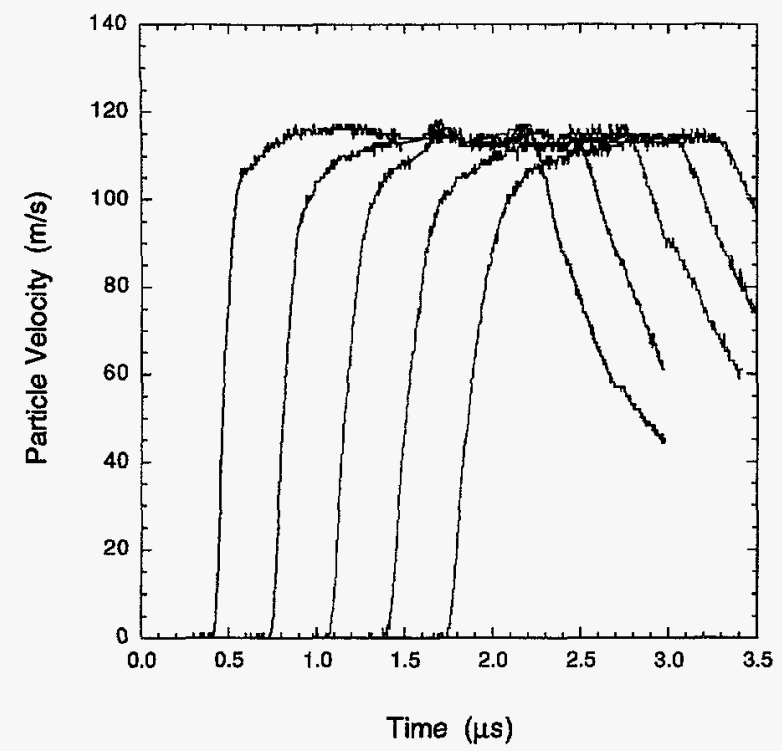

Figure 28: In-material MMV gauge records in PBX 9501 at $598 \mathrm{MPa}$ in a symmetric impact experiment, 1042. The PBX 9501 was ram-pressed at TA-9 from Holston lot 85G730-007. Gauge positions are 1.38 to $5.32 \mathrm{~mm}$ in from impact face. Half the impact velocity is $116 \mathrm{~m} / \mathrm{s}$.

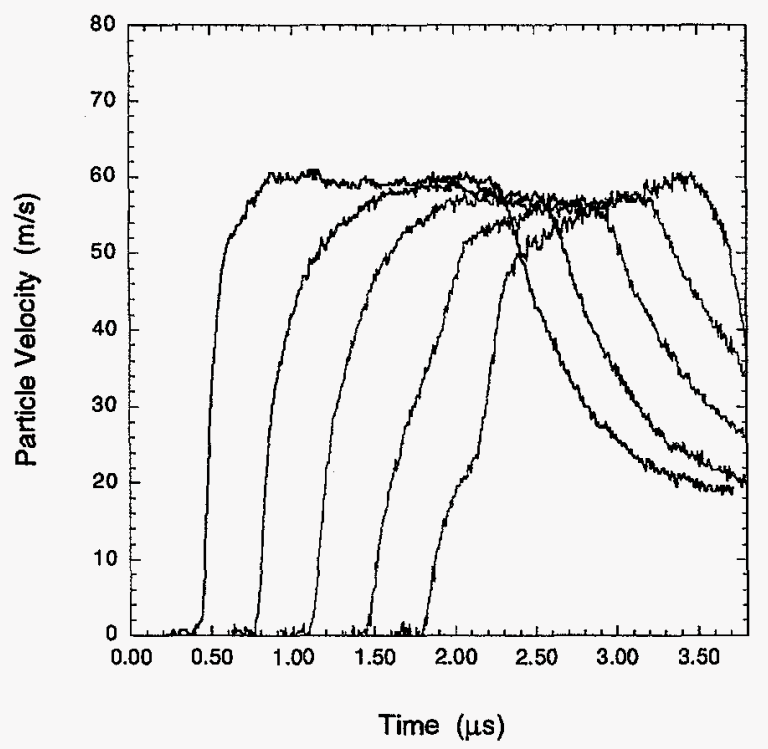

Figure 29: In-material MMV gauge records in PBX 9501 at about $300 \mathrm{MPa}$ in a symmetric impact experiment, 1059. Particle velocities are low, and the profiles appear distorted. However, they show the two-wave structure clearly. Gauge positions are 1.43 to $5.38 \mathrm{~mm}$ in from impact face. Half the impact velocity is $63.4 \mathrm{~m} / \mathrm{s}$. Sample density was $1.828 \mathrm{~g} / \mathrm{cm}^{3}$. individual components. PBX 9501 is 95 wt \% HMX in a bimodal distribution and 5 wt $\%$ binder. The binder is half estane and half nitroplasticizers. A small amount of antioxidant is added also.

\section{A. Hugoniot Data and Wave Profiles for PBX 9501 Binder and Estane}

Impact experiments were performed on the binder and estane from 200 to $1000 \mathrm{MPa}$. The binder is half estane, a polyester polyurethane elastomer, by weight. The results for Hugoniot states are summarized in Table 6. In the binder experiment 1085 at $1000 \mathrm{MPa}$ an accurate wave transit time was not obtained, since only one of the two PZT impact pins was recorded. However, a good wave profile was measured.

Hugoniot data for estane from 1.1 to $18 \mathrm{GPa}$ is given in Ref. 9. The fit of shock velocity vs particle velocity for that data is $U_{S}=2.32+1.70 u_{p}$. The intercept is significantly higher than the bulk sound speed of $1.75 \mathrm{~mm} / \mu \mathrm{s}$ (Table 2) computed from our measurements of longitudinal and shear sound speeds. In a simple material the bulk sound speed should agree with the intercept of the bulk Hugoniot. The previous data and the new data are plotted in Fig. 30. The new data clarifies the situation. They show that the low pressure Hugoniot has a different slope than the high pressure Hugoniot, and that the low pressure data agrees with the bulk sound speed as intercept. This clarifies a discrepancy noted in many polymers. 26

The estane data is shown as pressure vs volume in Fig. 31. It is quite compressible up to about $15 \%$ and then stiffens. Apparently the free volume is taken out so that interchain repulsions dominate at higher pressure. This may be affected by the degree of crosslinking. The Hugoniot data has been included in a thermodynamic Helmholtz potential by Ralph Menikoff. ${ }^{27}$ The low pressure data was described by treating estane as having $1.5 \%$ porosity in a $P_{x}-\alpha$ model. This 'porosity' may be thought of as existing at the interchain level.

The Hugoniot data for the binder are displayed in Fig. 30. The points extrapolate back to the bulk sound speed in a fashion similar to estane. It is to be expected 
Table 6: Results of VISAR Experiments on PBX 9501 Binder and Estane

\begin{tabular}{cccccccccc}
\hline $\begin{array}{c}\text { Shot } \\
\text { num. }\end{array}$ & $\begin{array}{c}\text { Sample } \\
\text { type }\end{array}$ & $\begin{array}{c}\text { Impactor, } \\
\mathrm{d} \\
(\mathrm{mm})\end{array}$ & $\begin{array}{c}\text { Thick- } \\
\text { ness } \\
(\mathrm{mm})\end{array}$ & $\begin{array}{c}u_{I} \\
(\mathrm{~mm} / \mu \mathrm{s})\end{array}$ & $\begin{array}{c}\mathrm{U}_{S} \\
(\mathrm{~mm} / \mu \mathrm{s})\end{array}$ & $\begin{array}{c}\mathrm{u}_{p}{ }^{b} \\
(\mathrm{~mm} / \mu \mathrm{s})\end{array}$ & $\begin{array}{c}\mathrm{P}_{x}{ }^{b} \\
(\mathrm{GPa})\end{array}$ & $\epsilon_{x}{ }^{b}$ & $\begin{array}{c}\mathrm{T} \\
\left({ }^{\circ} \mathrm{C}\right)\end{array}$ \\
\hline 1088 & binder & $\mathrm{TPX}, 5.33$ & 6.16 & 0.196 & 1.94 & 0.080 & 0.198 & 0.041 & 17.0 \\
1066 & binder & z-qtz, 6.37 & 4.49 & 0.179 & 2.13 & 0.154 & 0.420 & 0.072 & 20.2 \\
1085 & binder & z-qtz, 6.37 & 5.48 & 0.373 & - & - & - & - & - \\
1087 & estane & TPX, 5.55 & 10.018 & 0.1885 & 2.11 & 0.076 & 0.191 & 0.036 & 17.0 \\
1065 & estane & z-qtz, 6.37 & 5.07 & 0.145 & 2.31 & 0.124 & 0.345 & 0.054 & 19.0 \\
1080 & estane & z-qtz, 6.37 & 5.01 & 0.347 & 2.75 & 0.291 & 0.959 & 0.106 & 19.8 \\
\hline
\end{tabular}

${ }^{a}$ The binder samples were made at S-Site by pouring thin layers of lacquer into muffin tins and letting the solvent evaporate between pours. The binder material was assayed at $51.8 \mathrm{wt} \%$ estane and $48.2 \mathrm{wt} \%$ nitroplasticizer. By GPLC (gel-permeation liquid chromatography) the peak and average molecular weight of the estane in the binder were 119,000 and $153,000 \mathrm{~g} / \mathrm{mol}$, respectively. The estane samples were all hot-pressed under vacuum to about 1 ksi at S-Site from estane flakes from B. F. Goodrich Company. The pressed billets were 6 inches in diameter and 2 inches thick. The estane lot was 6812100 SK13. The average and peak molecular weights were about $73,000 \mathrm{~g} / \mathrm{mol}$.

${ }^{b}$ Values were calculated from the intersection of the Rayleigh line and the appropriate reflected impactor Hugoniot using the wave velocity in the sample at half maximum particle velocity, the measured impactor velocity and the known impactor Hugoniot.

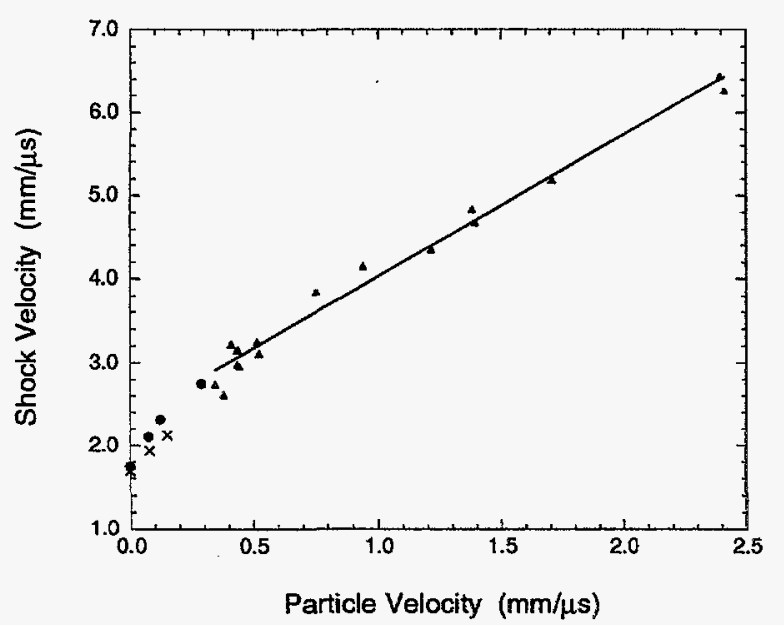

Figure 30: Shock velocity vs particle velocity Hugoniot data for estane and PBX 9501 binder. The blue points are the new data and measured bulk sound speed. The black triangles are from Marsh's compendium. The red exes are bulk sound speed and Hugoniot points for the binder.

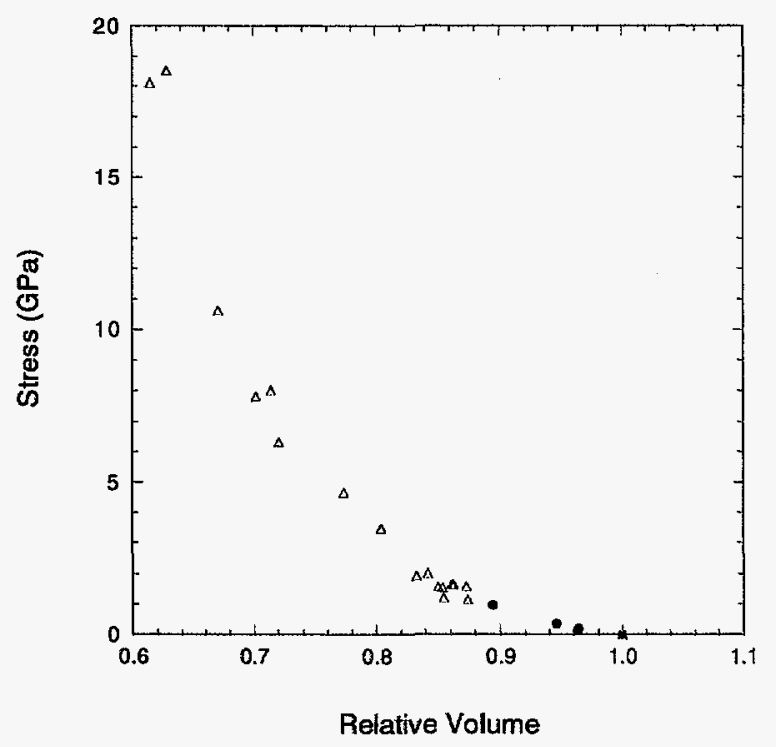

Figure 31: Pressure-volume Hugoniot for estane. The new data are the blue points. The others are from Marsh's compendium. 
that the $U_{S}$ vs $u_{p}$ Hugoniot will have a lower slope at higher pressures as is the case for most polymers including estane. ${ }^{26}$

The wave profiles from the VISAR experiments on the binder are displayed in Fig. 32. The window material, PMMA, has a higher shock impedance than the binder or estane. Therefore, shocks are reflected from the interface back into the sample, instead of the rarefactions experienced by PBX 9501 samples. The impact stresses for the three experiments are 198, 420 and $1040 \mathrm{MPa}$.

Using MACRAME and the measured Hugoniots the calculated interface particle velocities for the three experiments are $67.5,135$, and $293 \mathrm{~m} / \mathrm{s}$. The measured states behind the shock are 72,123 and $291 \mathrm{~m} / \mathrm{s}$, respectively. The intermediate experiment has a sharper wave front than the other two. The other two have more rounding before the final state. These two are probably more representative of the material.

The $420 \mathrm{MPa}$ experiment had a VISAR fringe constant of $176 \mathrm{~m} / \mathrm{s}$ per fringe, and the $198 \mathrm{MPa}$ experiment had a fringe constant of $96 \mathrm{~m} / \mathrm{s}$ per fringe. Thus both profiles were obtained from about $3 / 4$ of a fringe. The VISAR particle velocity accuracy depends on the number of fringes. With less than a fringe the accuracy is not good. The highest stress profile has three fringes in the shock rise and should be accurate to about $1 \%$. The gradual ramping of the low stress experiment and the late bumps on the experiment at the intermediate stress are probably artifacts of the experimental imprecision with less than a fringe of data.

There is $250 \mathrm{MHz}$ noise on the fringes due to shot noise in the photomultiplier tubes. For some experiments the fringe data was smoothed 5 points at a time to reduce the high frequency noise on the signal. The analysis program written by Will Hemsing avoids smoothing the sharp jumps.

Similarly, the estane profiles from VISAR experiments are shown in Fig. 33. The impact stresses determined from the measured shock speeds and the impactor velocity and Hugoniot are 191, 345, and $959 \mathrm{MPa}$. Using MACRAME and the measured Hugoniots the calculated interface par-

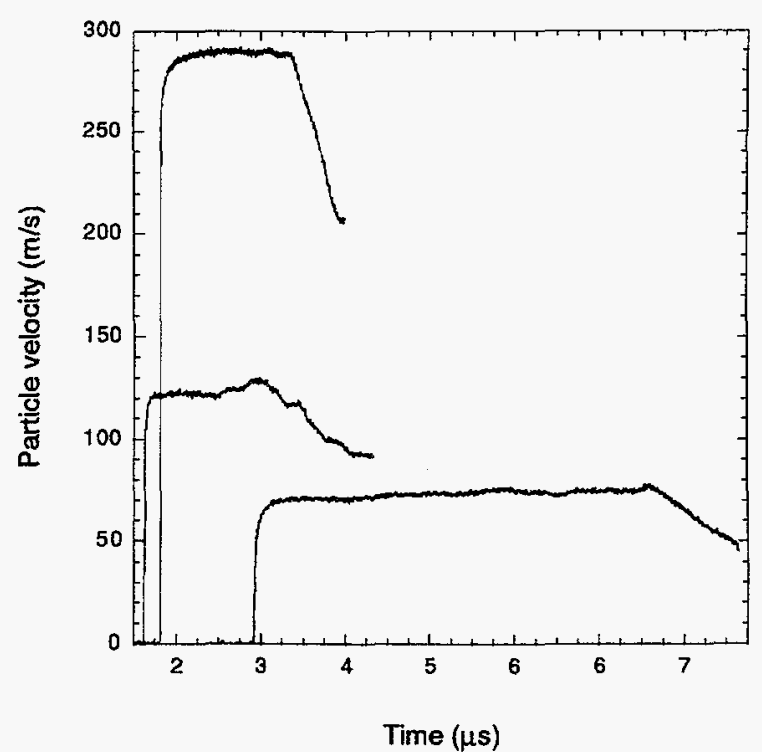

Figure 32: VISAR interface records for PBX 9501 binder at the interface with PMMA at 198, 420 , and $1040 \mathrm{MPa}$ impact stresses. For the experiment at $1040 \mathrm{MPa}$ the wave arrival time is estimated.

ticle velocities for the three experiments are 65,111 , and $271 \mathrm{~m} / \mathrm{s}$. The measured states behind the shock are 66 , 105 and $272 \mathrm{~m} / \mathrm{s}$, respectively.

As with the binder the two lower stress experiments had less than one fringe of data. The apparent oscillations are probably not due to the inherent impact response of estane. Besides the problem of experimental imprecision the samples were soft and difficult to machine to good tolerances of flatness and thickness uniformity. In assembling the target, epoxy was used to fill in any gaps due to deviations from flatness in the sample. Generally the samples were thickest in the center so that epoxy thickness was minimized at the laser spot on the mirror. The resultant effect of these sample imperfections on particle velocity measurement is magnified at low impact velocities as used for the experiments at 191 and $345 \mathrm{MPa}$.

The experiment at $959 \mathrm{MPa}$ should be accurate. The ramping rise behind the shock is quite marked, but the final state is in good agreement with a MACRAME calculation using measured Hugoniots. 


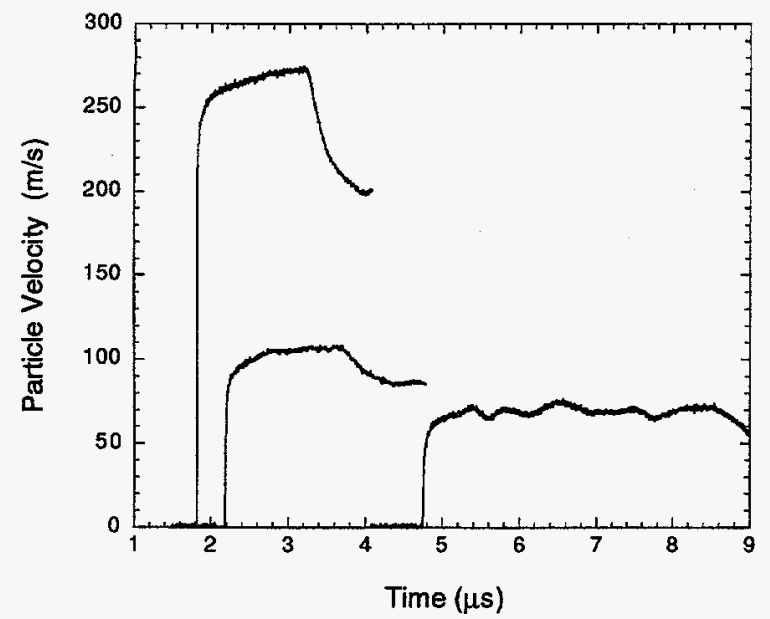

Figure 33: Particle velocity profiles for estane at the interface with PMMA. Impact stresses are 190, 340, and $959 \mathrm{MPa}$.

\section{B. Experiments on HMX Single Crystals}

Two VISAR experiments with PMMA windows were performed in order to measure the Hugoniot elastic limit of $\beta$-HMX crystals. The $3 \mathrm{~mm}$ thick crystals were mounted on $5 \mathrm{~mm}$ thick Kel-F discs and surrounded with an impedance matching mixture of epoxy and silica. The impact stress was about 1.4 GPa. The two orientations studied had faces parallel to the $\{110\}$ and $\{011\}$ crystal planes in $P 2_{1} / n$ space group. HMX $\beta$ phase is monoclinic. Crystallographers use $P 2_{1} / c$; crystal growers use $P 2_{1} / n$, while the slip systems of anthracene and other molecular crystals of the same space group are given in $P 2_{1} / a$. The revised international crystallography tables ${ }^{28}$ list space group $P 2_{1} / c$ with the other two as alternate choices of a coordinate system.

The orientations were determined by measuring interfacet angles with a protractor. By comparing a set of angles with computed ones, it was possible to determine the facets. Slabs were cut parallel to a facet with a diamond saw to prepare a sample for impact experiments. The $\{110\}$ crystal was $3.210 \mathrm{~mm}$ thick, and the $\{011\}$ crystal was $2.997 \mathrm{~mm}$ thick. The profiles at the interface with a PMMA window from the VISAR experiments are shown in Fig. 34. The $\{110\}$ orientation has an elastic- plastic profile similar to that seen in simple materials with some work hardening between the elastic and plastic waves. The $\{011\}$ orientation has a stress-relaxing profile similar to that observed in LiF, Armco iron, and other materials. $29,30,31$ The elastic shock strength decays until a steady value is reached.

Howard Cady performed early studies on quasi-static deformation of HMX. Twinning is an important deformation mechanism in $\beta$-HMX. The twin plane is (101). ${ }^{32}$ The twin direction has been postulated to be [101] ${ }^{33}$ Other deformation mechanisms may also contribute. The fracture plane is on planes of $\{011\}$ type. ${ }^{32}$ Slip planes (100) and (101) have been established with possible Burgers vectors of [100] and [101] ${ }^{33}$ The relationship of the impact plane to the deformation systems (plane and direction) will determine the elastic-plastic behavior. Here, the word 'plastic' is used loosely to cover the inelastic deformation. In an isotropic material the maximum resolved shear stress in uniaxial strain is at $45^{\circ}$ to the impact plane. The deformation system that has plane and direction closest to this will likely take most of the inelastic deformation, once the critical shear stress is exceeded. If the deformation mechanism has significant kinetics to it, stress relaxing behavior will be observed. Apparently different mechanisms and kinetics dominate in the two orientations studied.

Elastic precursor amplitudes were determined by using Rayleigh lines for the crystal elastic release isentrope to get from the interface state to the state in the crystal. For the $\{110\}$ crystal the velocity of the first disturbance was $4.25 \mathrm{~mm} / \mu \mathrm{s}$, and the velocity of the elastic wave at half maximum particle velocity was $4.16 \mathrm{~mm} / \mu \mathrm{s}$. This is substantially larger than the longitudinal sound speed (Table 2). This implies that the crystal is nonlinearly elastic; it stiffens in response to increasing impact stress. Similar behavior was observed in PETN crystals. ${ }^{34}$ The elastic state in HMX was determined to be $460 \mathrm{MPa}$ and $58 \mathrm{~m} / \mathrm{s}$. The plastic wave had a Lagrangian wave speed of $3.28 \mathrm{~mm} / \mu \mathrm{s}$ and a rise time from 10 to $90 \%$ of 123 ns. The plastic waves in PETN were unsteady. ${ }^{19}$

For the $\{011\}$ crystal the speed of the initial disturbance was $4.07 \mathrm{~mm} / \mu \mathrm{s}$ and $4.04 \mathrm{~mm} / \mu \mathrm{s}$ for half maximum on 


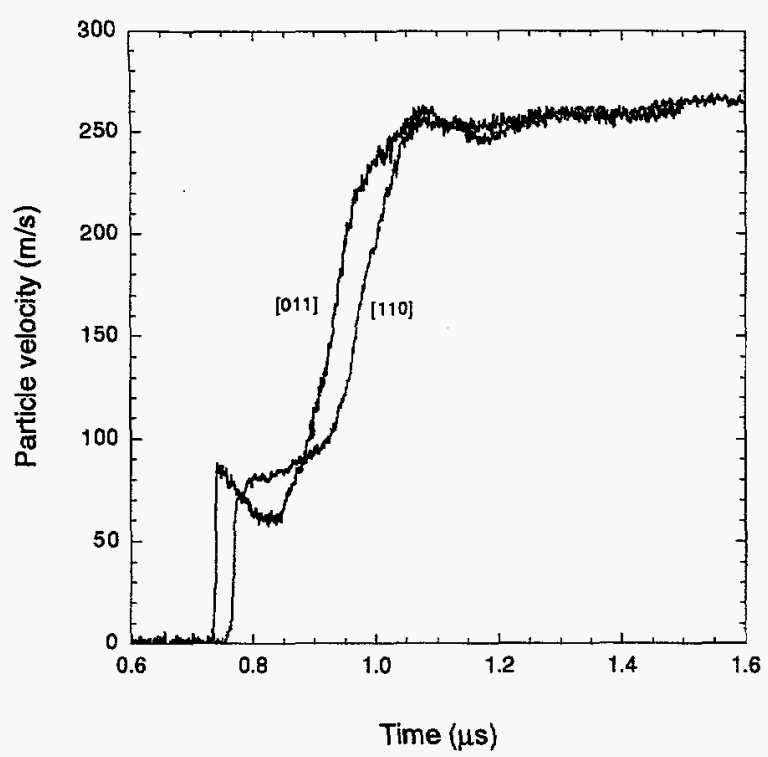

Figure 34: Particle velocity profiles at the HMX/PMMA interface from VISAR experiments for crystals with [110] and [011] faces. The elastic precursor wave is evident.

the elastic wave. In comparison, the measured longitudinal sound speed is $3.72 \mathrm{~mm} / \mu \mathrm{s}$. The elastic state in this orientation was computed to be $490 \mathrm{MPa}$ and $64 \mathrm{~m} / \mathrm{s}$. At the HMX/PMMA interface the elastic state relaxes from $86 \mathrm{~m} / \mathrm{s}$ down to $62 \mathrm{~m} / \mathrm{s}$ in about $70 \mathrm{~ns}$. The plastic wave has a rise time of $123 \mathrm{~ns}$, the same value as the other orientation. The measured Lagrangian plastic wave was 3.21 $\mathrm{mm} / \mu$ s speed, very close to the value for the $\{110\}$ orientation. The Lagrangian wave speed converts to an Eulerian wave speed of $3.22 \mathrm{~mm} / \mu \mathrm{s}$. So the two orientations have similar but not identical elastic-plastic responses to impact. More experimental work is needed to delineate the details of the behavior.

\section{ACKNOWLEDGMENTS}

Jim N. Johnson provided helpful conversations, guidance, and sample calculations. Deanne Idar provided data and helpful comments. Thanks to Joe Fritz for teaching Jerry Dick how to use his characteristics code MACRAME. Some of the experiments were built by Dennis Price and Dave Kachelmeier.

\section{REFERENCES}

1. S. K. Chidester, C. M. Tarver, and C. G. Lee, in Shock Compression in Condensed Matter-1997, (AIP, Woodbury, NY, 1998), to be published.

2. B. W. Asay, G. W. Laabs, B. F. Henson, and D. J. Funk, J. Appl. Phys. 82, 1093 (1997).

3. C. A. Forest, J. Wackerle, J. J. Dick, S. A. Sheffield, and D. R. Pettit Ninth Symposium (International) on Detonation (Office of Naval Research, Arlington, VA, 1989), p. 683 .

4. Willard F. Hemsing, Rev. Sci. Instrum. 50, 73 (1979).

5. Los Alamos data compiled in LASL Explosive Property Data, edited by T. R. Gibbs and A. Popolato (University of California Press, Berkeley, 1980), pp. 353-4.

6. D. J. Idar, private communication, 1997.

7. E. B. Orler and D. A. Wrobleski, private communication, 1997.

8. J. Zaug, private communication, 1997.

9. S. P. Marsh, LASL Hugoniot Data, (University of California Press Berkeley, 1980), pp. 621-2.

10. G. R. Fowles, J. Appl. Phys. 32, 1475 (1961).

11. B. Olinger and J. W. Hopson, in Symposium H.D.P. (Commissariat a l'Energie Atomique, Saclay, 1978), p. 9 .

12. E. R. Lemar, J. W. Forbes, J. W. Watt, and W. L. Elban, J. Appl. Phys. 58, 3404 (1985).

13. J. J. Dick, C. A. Forest, J. B. Ramsay, and W. L. Seitz, J. Appl. Phys. 63, 4881 (1988).

14. L. C. Chhabildas and M. E. Kipp, Eighth Symposium (International) on Detonation, edited by J. M. Short (Naval Surface Weapons Center, Washington, DC, 1986), p. 274.

15. V. Krishna Mohan, V. C. Jyothi Bhasu, and J. E. Field, Ninth Symposium (International) on Detonation (Office of Naval Research, Arlington, VA, 1989), p. 1276.

16. G. T. Gray, W. R. Blumenthal, C. M. Cady, and D. J. Idar, in Shock Compression in Condensed Matter1997, (AIP, Woodbury, NY, 1998), to be published.

17. B. M. Dobratz and P. C. Crawford, LLNL Explosives Handbook, UCRL-52997 Change 2, pp. 7-10 (1985).

18. D. Wiegand, in Shock Compression in Condensed Matter-1997, (AIP, Woodbury, NY, 1998), to be published.

19. J. J. Dick and J. P. Ritchie, J. Appl. Phys. 76, 2726 (1994). 
20. J. W. Swegle and D. E. Grady, J. Appl. Phys. 58, 692 (1985).

21. G. R. Fowles and R. F. Williams, J. Appl. Phys. 41, 360 (1970); G. R. Fowles in Dynamic Response of Materials to Intense Impulsive Loading edited by P. C. Chou and A. K. Hopkins (Air Force Materials Laboratory, Wright Patterson AFB, 1973), p. 416.

22. M. Cowperthwaite and R. F. Williams, J. Appl. Phys. 42, 456 (1971).

23. D. E. Grady and M. E. Kipp in High-Pressure Shock Compression of Solids, edited by J. R. Asay and M. Shahinpoor (Springer-Verlag, New York, 1993), p. 271.

24. S. J. P. Palmer, J. E. Field, and J. M. Huntley, Proc. Roy. Soc. Lond. A 440, 399 (1993).

25. G. I. Kanel', A. V. Utkin, and Z. G. Toltstikova, in High-Pressure Science and Technology-1993, edited by S. C. Schmidt, J. W. Shaner, G. A. Samara and M. Ross (AIP Press, New York, 1994), p. 1123.

26. C. E. Morris, J. N. Fritz, and R. G. McQueen, J. Appl. Phys. 80, 5203 (1984); W. J. Carter and S. P. Marsh, "Hugoniot Equation of State of Polymers," Los Alamos Report LA-13006-MS, (1995).

27. R. T. Menikoff, private communication, 1997.

28. T. Hahn, International Tables for Crystallography, edited by T. Hahn (Kluwer Academic Publishers, Dordrecht, Boston, London, 1995), Vol. A, p. 174.

29. J. R. Asay, G. R. Fowles, G. E. Duvall, and M. H. Miles, J. Appl. Phys. 43, 2132 (1972).

30. J. W. Taylor, J. Appl. Phys. 36, 3146 (1963).

31. J. N. Johnson, O. E. Jones, and T. E. Michaels, J. Appl. Phys. 41, 2330 (1970).

32. S. J. P. Palmer, and J. E. Field, Proc. Roy. Soc. Lond. A 383, 399 (1982).

33. D. B. Sheen, J. N. Sherwood, H. G. Gallagher, A. H. Littlejohn, and A. Pearson, Final Report to the U. S. Office of Naval Research, "An Investigation of Mechanically Induced Lattice Defects in Energetic Materials," (University of Strathclyde, Glasgow, 1993), p. 29.

34. J. J. Dick, J. Appl. Phys. 81, 601 (1997). 